\title{
The accommodation coefficient of water molecules on ice - cirrus cloud studies at the AIDA simulation chamber
}

\author{
J. Skrotzki ${ }^{1, *}$, P. Connolly ${ }^{2}$, M. Schnaiter ${ }^{1}$, H. Saathoff ${ }^{1}$, O. Möhler ${ }^{1}$, R. Wagner ${ }^{1}$, M. Niemand ${ }^{1}$, V. Ebert ${ }^{3,4}$, and \\ T. Leisner ${ }^{1}$ \\ ${ }^{1}$ Institute for Meteorology and Climate Research - Atmospheric Aerosol Research, Karlsruhe Institute of Technology (KIT), \\ Karlsruhe, Germany \\ ${ }^{2}$ School of Earth, Atmospheric and Environmental Sciences, University of Manchester, Manchester, UK \\ ${ }^{3}$ Physikalisch-Technische Bundesanstalt, Braunschweig, Germany \\ ${ }^{4}$ Center of Smart Interfaces, Technische Universität Darmstadt, Darmstadt, Germany \\ *Invited contribution by J. Skrotzki, recipient of the EGU Union Outstanding Student Poster Award 2011.
}

Correspondence to: H. Saathoff (harald.saathoff@kit.edu)

Received: 29 June 2012 - Published in Atmos. Chem. Phys. Discuss.: 18 September 2012

Revised: 25 March 2013 - Accepted: 3 April 2013 - Published: 29 April 2013

\begin{abstract}
Cirrus clouds and their impact on the Earth's radiative budget are subjects of current research. The processes governing the growth of cirrus ice particles are central to the radiative properties of cirrus clouds. At temperatures relevant to cirrus clouds, the growth of ice crystals smaller than a few microns in size is strongly influenced by the accommodation coefficient of water molecules on ice, $\alpha_{\text {ice }}$, making this parameter relevant for cirrus cloud modeling. However, the experimentally determined magnitude of $\alpha_{\text {ice }}$ for cirrus temperatures is afflicted with uncertainties of almost three orders of magnitude, and values for $\alpha_{\text {ice }}$ derived from cirrus cloud data lack significance so far. This has motivated dedicated experiments at the cloud chamber AIDA (Aerosol Interactions and Dynamics in the Atmosphere) to determine $\alpha_{\text {ice }}$ in the cirrus-relevant temperature interval between $190 \mathrm{~K}$ and $235 \mathrm{~K}$ under realistic cirrus ice particle growth conditions. The experimental data sets have been evaluated independently with two model approaches: the first relying on the newly developed model SIGMA (Simple Ice Growth Model for determining Alpha), the second one on an established model, ACPIM (Aerosol-Cloud-Precipitation Interaction Model). Within both approaches a careful uncertainty analysis of the obtained $\alpha_{\text {ice }}$ values has been carried out for each AIDA experiment. The results show no significant dependence of $\alpha_{\text {ice }}$ on temperature between $190 \mathrm{~K}$ and $235 \mathrm{~K}$. In addition, we find no evidence for a dependence of $\alpha_{\text {ice }}$
\end{abstract}

on ice particle size or on water vapor supersaturation for ice particles smaller than $20 \mu \mathrm{m}$ and supersaturations of up to $70 \%$. The temperature-averaged and combined result from both models is $\alpha_{\text {ice }}=0.7_{-0.5}^{+0.3}$, which implies that $\alpha_{\text {ice }}$ may only exert a minor impact on cirrus clouds and their characteristics when compared to the assumption of $\alpha_{\text {ice }}=1$. Impact on prior calculations of cirrus cloud properties, e.g., in climate models, with $\alpha_{\text {ice }}$ typically chosen in the range $0.2-1$ is thus expected to be negligible. In any case, we provide a well-constrained $\alpha_{\text {ice }}$ which future cirrus model studies can rely on.

\section{Introduction}

Cirrus clouds play a major role in the radiative budget of the Earth's atmospheric system through their interactions with incident solar and surface-emitted terrestrial radiation (Liou, 1986). The radiative properties of cirrus clouds strongly depend on ice particle size, shape, and number concentration (Zhang et al., 1999). Ice particle properties and number concentration in cirrus clouds depend, besides other influences, on ice particle growth rates (Lin et al., 2002). One of the main parameters governing the growth of ice particles up to a size of few micrometers, i.e., in the initial stage of ice particle 
Table 1. Selection of laboratory measurements of the accommodation coefficient $\alpha_{\text {ice }}$ at temperatures relevant for cirrus clouds. Results are spread over almost three orders of magnitude. Previous studies are summarized in Choularton and Latham (1977), Haynes et al. (1992), and Pruppacher and Klett (1997).

\begin{tabular}{|c|c|c|c|}
\hline$\alpha_{\text {ice }}$ & Temp. $[\mathrm{K}]$ & Method & Reference \\
\hline $1.06 \pm 0.1>\alpha_{\text {ice }}>0.65 \pm 0.08$ & $20-185$ & Ice layer growth & Haynes et al. (1992) \\
\hline $0.5 \pm 0.1<\alpha_{\text {ice }}<1.4 \pm 0.2$ & $211-232$ & $\begin{array}{l}\text { Ice layer } \\
\text { sublimation }\end{array}$ & $\begin{array}{l}\text { Kramers and } \\
\text { Stemerding (1951) }\end{array}$ \\
\hline $0.3_{-0.1}^{+0.7}$ & 200 & Ice layer growth & Leu (1988) \\
\hline $0.48 \pm 0.04>\alpha_{\text {ice }}>0.08 \pm 0.03$ & $140-210$ & $\begin{array}{l}\text { Condensed ice } \\
\text { sample growth }\end{array}$ & Pratte et al. (2006) \\
\hline $0.031 \pm 0.001$ & $234-236$ & $\begin{array}{l}\text { Frozen droplet } \\
\text { growth }\end{array}$ & Earle et al. (2010) \\
\hline $0.06<\alpha_{\text {ice }}<0.07$ & $200-219$ & Ice crystal growth & Isono and Iwai (1969) \\
\hline $0.004 \pm 0.002<\alpha_{\text {ice }}<0.009 \pm 0.003$ & $213-233$ & $\begin{array}{l}\text { Frozen droplet } \\
\text { growth }\end{array}$ & Magee et al. (2006) \\
\hline
\end{tabular}

growth in cirrus clouds (in the kinetic growth regime), is the accommodation coefficient of water molecules on ice.

This accommodation coefficient $\alpha_{\text {ice }}$, also known as the deposition coefficient, is defined as the sticking probability of water molecules that collide with an ice surface, e.g., of an ice particle. In the following discussion, $\alpha_{\text {ice }}$ will be referred to as the ice accommodation coefficient or simply the accommodation coefficient, for brevity.

Cirrus cloud model calculations have shown that use of $\alpha_{\text {ice }}$ values below 0.1 going down to 0.001 can lead to a significant increase in ice number concentration by several orders of magnitude when compared to simulations using $\alpha_{\text {ice }}=1$ (Lin et al., 2002; Gierens et al., 2003). In contrast, lowering $\alpha_{\text {ice }}$ from 1 to 0.1 had only little impact on the model results. The reason for the increase in ice number concentration for very low $\alpha_{\text {ice }}$ values will be outlined in the following.

Supersaturations with respect to ice in the upper troposphere may arise by the lifting of an air parcel and the resulting nearly adiabatic cooling. Ice nucleation, i.e., the formation of an ice particle by an aerosol particle, requires that a certain supersaturation threshold is exceeded. After ice nucleation has set in, the growing ice particles tend to deplete the supersaturation. Hence, the reason that models predict increasing ice number concentrations with decreasing $\alpha_{\text {ice }}$ is that lower values of $\alpha_{\text {ice }}$ would lead to a higher suppression of ice particle growth in cirrus clouds. This suppression in the growth would result in a higher peak supersaturation and a longer time during which the supersaturation is able to stay above the nucleation threshold, allowing more of the ice nuclei to be activated or more of the aerosols to freeze by homogeneous nucleation within the cloud. This increased ice number concentration would enhance optical depth and albedo of cirrus clouds, i.e., the radiative properties, in a similar way to the well-known Twomey effect for "warm" clouds (Lohmann and Feichter, 2005; Twomey, 1974). In addition, the ice growth suppression would lead to higher, more per- sistent supersaturations. For such high persisting supersaturations that have been observed in cirrus clouds, a very low ice accommodation coefficient could indeed serve as explanation (Gao et al., 2004; Peter et al., 2006).

The outlined potential impact on the ice particle growth and the properties of cirrus clouds make $\alpha_{\text {ice }}$ a relevant parameter in cirrus cloud modeling. It is included not only in the formalisms for cloud ice formation in general circulation models (Kärcher et al., 2006; Kärcher and Lohmann, 2002a, b, 2003; Morrison and Gettelman, 2008) but also in more detailed models (Cotton et al., 2007; Spichtinger and Gierens, 2009; Haag et al., 2003).

However, $\alpha_{\text {ice }}$ is not well constrained experimentally so far, with experimental values ranging from the order of $10^{-3}$ up to unity. For a comprehensive summary of experimental results for $\alpha_{\text {ice }}$ from laboratory measurements, see Choularton and Latham (1977), Haynes et al. (1992), and Pruppacher and Klett (1997). A selection of laboratory studies that were performed at temperatures relevant for the ice growth in cirrus clouds is given in Table 1 . With respect to the applied experimental approach, they can be divided into two groups.

One approach observes the growth or sublimation of an ice layer or sample. Note that in the framework of ice growth used in this work (cf. Sect. 2), the sublimation coefficient equals the ice accommodation coefficient by definition. These measurements are typically carried out under pressures of less than $1 \mathrm{~Pa}$, e.g., in an ultrahigh-vacuum chamber or a low-pressure flow reactor. Under these conditions, the ice growth or sublimation rates, respectively, are directly proportional to $\alpha_{\text {ice }}$. Ice growth/sublimation rates are, e.g., determined gravimetrically (Kramers and Stemerding, 1951) by interferometric measurement of the thickness of a plane ice layer (Haynes et al., 1992) or by measurement of the molecular water vapor flux to the ice surface through mass spectroscopic techniques (Leu, 1988; Pratte et al., 2006). These experiments typically yield results of $\alpha_{\text {ice }}>0.1$ for cirrus cloud temperatures. However, the ice samples investigated 
Table 2. Overview of cirrus cloud model studies with their preferred values or ranges for the accommodation coefficient $\alpha_{\text {ice }}$. Studies include the examination of atmospheric cirrus clouds and of simulated cirrus clouds in cloud chamber experiments.

\begin{tabular}{lrll}
\hline$\alpha_{\text {ice }}$ & Temp. [K] & Study & Reference \\
\hline $0.01<\alpha_{\text {ice }}<0.1$ & 225 & Atmospheric, local & Gierens et al. (2003) \\
0.2 preferred over 0.05 & $210-235$ & Atmospheric, local & Kärcher and Ström (2003) \\
$>0.1$ & 225 & Atmospheric, local & Kay and Wood (2008) \\
0.5 preferred over 0.006 & $<238$ & Atmospheric, global & Lohmann et al. (2008) \\
$>0.2$ & 202 & Cloud chamber & Haag et al. (2003) \\
0.1 preferred over 1 & $180-200$ & Cloud chamber & Saunders et al. (2010) \\
\hline
\end{tabular}

are much larger and of different appearance than typical cirrus cloud ice particles.

The other approach optically monitors the growth of single droplets, frozen by the homogeneous nucleation of ice, which are electrodynamically levitated in vertical wind tunnels (Earle et al., 2010; Magee et al., 2006) or the growth of single ice crystals on a substrate (Isono and Iwai, 1969). These three experiments obtained $\alpha_{\text {ice }}$ values far below 0.1 . The value retrieved by Earle et al. (2010) is $\alpha_{\text {ice }}=0.031$, the result by Isono and Iwai (1969) is $0.06<\alpha_{\text {ice }}<0.07$, and the results by Magee et al. (2006) suggest very low $\alpha_{\text {ice }}$ values in the range 0.004-0.009.

In addition to these laboratory measurements, there are several cirrus cloud model studies, summarized in Table 2, which vary $\alpha_{i c e}$ in model calculations until good agreement between model output and observational data, i.e., measured ice number concentrations or ice supersaturations, is achieved. These studies have either investigated atmospheric cirrus cloud data from in situ airborne measurements (Gierens et al., 2003; Kärcher and Ström, 2003; Kay and Wood, 2008), global satellite retrievals of cloud properties (Lohmann et al., 2008) or simulated cirrus clouds in cloud chamber experiments (Haag et al., 2003; Saunders et al., 2010). All except the study by Gierens et al. (2003) are in favor of an accommodation coefficient greater than 0.1. Based on the results of these studies, $\alpha_{\text {ice }}$ is generally assumed in the range $0.2-1$ for the parameterization of cirrus ice particle growth in all the different types of models mentioned previously. However, $\alpha_{\text {ice }}$ values have either been retrieved for very limited data sets at one specific temperature (Gierens et al., 2003; Kay and Wood, 2008; Haag et al., 2003) or the magnitude of $\alpha_{\text {ice }}$ has not been stated to any level of precision (Kärcher and Ström, 2003; Lohmann et al., 2008; Saunders et al., 2010). Moreover, none of these analyses have performed a thorough uncertainty analysis for their retrieved $\alpha_{\text {ice }}$ values.

The reasons for the wide spread of values for the ice accommodation coefficient obtained by different experimental measurements and model studies remains unknown. Some rather speculative explanations have been brought forward such as that $\alpha_{\text {ice }}$ could depend on particle size (Gierens et al., 2003; Magee et al., 2006) or supersaturation (Nelson and Baker, 1996) or that reactions on the ice particle sur- face take place which inhibit the incorporation of water vapor molecules (Gao et al., 2004).

Due to the specified relevance of the ice accommodation coefficient, $\alpha_{\text {ice, }}$, in cirrus cloud modeling, dedicated $\alpha_{\text {ice }}$ measurements were carried out at the aerosol and cloud chamber AIDA (Aerosol Interactions and Dynamics in the Atmosphere) by experimentally simulating the formation and evolution of cirrus ice particles under realistic conditions. These experiments are described in Sect. 3, before which we present a brief summary of the theoretical description of atmospheric ice particle growth in Sect. 2. In order to determine $\alpha_{\text {ice }}$ values from the AIDA experiments, two different model approaches were applied. The methods of these approaches are described in Sect. 4. Combined experimental and modeling data are presented in Sect. 5. In addition, this section includes a careful uncertainty analysis in order to set appropriate lower bounds on $\alpha_{\text {ice }}$. The results of our study to determine $\alpha_{\text {ice }}$ for cirrus ice particle growth are presented and discussed in Sect. 6. Section 7 concludes this paper.

\section{Atmospheric ice particle growth}

Mass transfer of water molecules to the surface of atmospheric ice particles determines the process of their growth. The mathematical expressions for the description of this mass transfer are outlined in this section.

Three cases or regimes for ice particle growth have to be distinguished dependent on the (volume equivalent) particle radius, $r_{\mathrm{p}}$, in relation to the mean free path of water vapor molecules in air $\lambda_{\mathrm{w}}$. It is useful to define the Knudsen number $K n$ in this context:

$K n=\frac{\lambda_{\mathrm{w}}}{r_{\mathrm{p}}}$.

The Knudsen number is used to distinguish between the different regimes of ice particle growth. If $K n \gg 1$, mass transport is determined by elementary gas kinetic processes in the so-called kinetic regime. In this regime the accommodation coefficient $\alpha_{\text {ice }}$ plays a dominant role. On the other hand, if $K n \ll 1$, the flux of water molecules to the ice particle is governed by diffusion in the so-called continuum regime. The determinant quantity in this regime is the diffusivity of 
water molecules in air, $D_{\mathrm{w}}$, given by (Hall and Pruppacher, 1976)

$D_{\mathrm{w}}=D_{\mathrm{w}, 0} \frac{p_{0}}{p}\left(\frac{T_{\mathrm{g}}}{T_{0}}\right)^{\gamma}$,

where $p$ is the gas pressure, $T_{\mathrm{g}}$ the gas temperature, and $D_{\mathrm{w}, 0}$ the diffusivity at $p_{0}=1013.25 \mathrm{hPa}$ and $T_{0}=273.15 \mathrm{~K}$. The temperature coefficient $\gamma$ and $D_{\mathrm{w}, 0}$ were estimated by Hall and Pruppacher (1976) for the temperature range 233-313 K to 1.94 and $0.211 \mathrm{~cm}^{2} \mathrm{~s}^{-1}$, respectively. We used the quite common empirical parameterization from Hall and Pruppacher (1976) since it results in only about $8 \%$ lower diffusivity values compared to a more recent analysis of experimental data by Massman (1998). Please note that values calculated with a Lennard-Jones model are 20-30\% lower (Ghosh et al., 2007), which would lead to even higher accommodation coefficients if applied in our analysis.

The intermediate regime between kinetic and continuum regime is called transition regime $(K n \approx 1)$ and connects the mass transfer formulation of both limiting cases. For atmospheric conditions relevant for cirrus clouds, $\lambda_{\mathrm{w}}$ typically takes values of $200 \mathrm{~nm}$ and above. This means that ice particles in natural cirrus clouds stay in the kinetic and intermediate regime until they are a few micrometers in size.

In order to connect the kinetic regime with the continuum regime, one can apply the so-called flux-matching approach for the transition regime (Pruppacher and Klett, 1997, Chap. 13). This approach assumes that for distances away from the ice particle surface smaller than the vapor jump length, $\Delta_{v}$, which is typically chosen to be of the order of $\lambda_{w}$, water vapor transport is governed by elementary gas kinetic mechanisms, i.e., the kinetic regime applies. For distances greater than $\Delta_{V}$, on the other hand, water vapor transport is governed by diffusion and the continuum regime is valid. At the boundary defined by $r=r_{\mathrm{p}}+\Delta_{\mathrm{v}}$, the water vapor fluxes of both regimes have to be matched.

With this approach, ice particle growth within the transition regime is described by a modified version of the water vapor diffusivity $D_{\mathrm{w}}$ from Eq. (2), so called $D_{\mathrm{w}}^{*}$. $D_{\mathrm{w}}^{*}$ is given by (Pruppacher and Klett, 1997; Eqs. 13-14)

$D_{\mathrm{w}}^{*}=\frac{D_{\mathrm{w}}}{\frac{r_{\mathrm{p}}}{r_{\mathrm{p}}+\Delta_{\mathrm{v}}}+\frac{4 D_{\mathrm{w}}}{\alpha_{\mathrm{ice}} r_{\mathrm{p}} \bar{c}_{\mathrm{w}}}}$,

where $\bar{c}_{\mathrm{W}}$ is the mean thermal speed of water vapor molecules. It is given by (Pruppacher and Klett, 1997; Eqs. 5-49)

$\bar{c}_{\mathrm{W}}=\frac{8 R T_{\mathrm{g}}}{\pi M_{\mathrm{w}}}{ }^{1 / 2}$,

with the universal gas constant $R$ and the molar mass of water $M_{\mathrm{w}}$. From Eq. (3), one obtains the limiting cases of the continuum as well as the kinetic regime for the corresponding limits of $r_{\mathrm{p}}$. In the limit $r_{\mathrm{p}} \rightarrow \infty, D_{\mathrm{w}}^{*} \rightarrow D_{\mathrm{w}}$ (continuum regime). In the limit $r_{\mathrm{p}} \rightarrow 0, D_{\mathrm{w}}^{*} \rightarrow \alpha_{\mathrm{ice}} r_{\mathrm{p}} \bar{c}_{\mathrm{w}} / 4$ (kinetic regime), where $\alpha_{\text {ice }}$ plays a dominant role.
Together with $D_{\mathrm{w}}^{*}$ the mass growth rate of an ice particle mainly depends on the water vapor saturation ratio with respect to ice, $S_{\text {ice. }}$. It is defined by

$S_{\text {ice }}=\frac{e}{\hat{e}_{\text {ice }}\left(T_{\mathrm{g}}\right)}$,

where $e$ is the water vapor partial pressure far away from the ice particle and $\hat{e}_{\text {ice }}\left(T_{\mathrm{g}}\right)$ the saturation vapor pressure with respect to ice as function of the gas temperature $T_{\mathrm{g}}$. According to Pruppacher and Klett (1997; Eqs. 13-76), the ice particle mass growth rate is given by

$\frac{\mathrm{d} m_{\mathrm{p}}}{\mathrm{d} t}=\frac{4 \pi C\left(S_{\text {ice }}-1\right)}{\frac{R T_{\mathrm{g}}}{\hat{e}_{\text {ice }}\left(T_{\mathrm{g}}\right) D_{\mathrm{w}}^{*} M_{\mathrm{w}}}+\mathrm{LH}}$,

where $m_{\mathrm{p}}$ is the ice particle mass, $C$ the electrostatic capacitance of the ice particle divided by $4 \pi \epsilon_{0}$ and referred to as the capacitance, and LH describes the effect of latent heat release from deposition of water molecules on the surface of the ice particle. However, the impact of LH is rather low for $T_{\mathrm{g}}<235 \mathrm{~K}$, i.e., for the growth of ice particles in cirrus clouds. LH affects the result of Eq. (6) by around $5 \%$ at $T_{\mathrm{g}}=235 \mathrm{~K}$ and this effect decreases with decreasing temperature. Therefore, $\mathrm{LH}$ will not be described in detail here, but in Appendix A.

The ice particle capacitance, $C$, depends on the ice particle shape. For spherical ice particles it is simply given by the particle's radius $r_{\mathrm{p}}$. More complex expressions for the capacitance of spheroid ice particles are given in McDonald (1963), and good approximations for cylinders and hexagonal columns have been determined numerically by Westbrook et al. (2008). In general, the consideration of nonspherical ice particle shapes is of importance for high aspect ratios. For compact ice particles with aspect ratios up to approximately two, the assumption of spherical ice particles causes an error in ice particle capacitance of $\sim 10 \%$ at most.

\section{Experimental methods}

For the determination of the ice accommodation coefficient $\alpha_{\text {ice }}$, dedicated experiments at the cloud chamber AIDA (Möhler et al., 2003, 2006) with simulated cirrus clouds in the temperature range between $190 \mathrm{~K}$ and $235 \mathrm{~K}$ have been performed. The ice particles were created by deposition nucleation (Möhler et al., 2006) on synthetic hematite aerosol particles as well as graphite spark generator (GSG) soot. The utilization of deposition nucleation allowed very small initial sizes of the ice particles, below $100 \mathrm{~nm}$, which resulted in the experiments having a high sensitivity to $\alpha_{\text {ice. }}$. Cooling rates during the dynamic expansion experiments were between $0.5 \mathrm{~K} \mathrm{~min}^{-1}$ and $2.7 \mathrm{~K} \mathrm{~min}^{-1}$, and experimental peak supersaturations varied between moderate supersaturations and supersaturations close to the homogeneous freezing threshold of supercooled solution droplets (Koop et al., 2000). These 
conditions are characteristic of cirrus clouds formed by orographic waves (Field et al., 2001; Gayet et al., 2006) and resulted in realistic cirrus ice particle growth yielding representative particle sizes and shapes (cf. the discussion on ice particle shapes in Sect. 4).

In the following, an overview of the AIDA chamber and the instrumentation relevant to this work, the aerosol types utilized in the experiments, and the experimental parameters and methods will be given.

\subsection{AIDA instrumentation and aerosol types}

The AIDA chamber consists of an aluminum vacuum vessel with a diameter of $4 \mathrm{~m}$, a height of $7.5 \mathrm{~m}$, and a volume of $84.3 \mathrm{~m}^{3}$. This large volume keeps boundary effects from the aluminum wall such as temperature and humidity gradients confined to a small fraction of the total volume. The vessel is placed in an isolating and thermostated housing which allows an operation temperature range between $-90^{\circ} \mathrm{C}$ and $+60^{\circ} \mathrm{C}$. The gas temperature inside the AIDA chamber is measured to an accuracy of $\pm 0.3 \mathrm{~K}$ (Möhler et al., 2006). A mixing fan maintains homogeneous conditions in the gas volume inside the vessel, which results in temperature differences of less than $\pm 0.2 \mathrm{~K}$ within the entire gas volume under static conditions (Möhler et al., 2006). Two vacuum pumps allow gas pressures from ambient pressure down to $0.01 \mathrm{hPa}$. Available cooling rates range from $0.1 \mathrm{~K} \mathrm{~min}^{-1}$ to $6 \mathrm{~K} \mathrm{~min}^{-1}$ and are a result of nearly adiabatic cooling by gas pressure reduction due to pumping. This cooling process is used in AIDA experiments to simulate the quasi-adiabatic expansion cooling that ascending air parcels experience in the atmosphere.

A detailed description of the AIDA instrumentation is given in Wagner et al. (2009). The instrumentation relevant to the cirrus ice growth experiments presented in this paper is depicted in Fig. 1 and consists of the following:

\subsubsection{Humidity}

For the in situ measurement of water vapor concentration and partial pressure, respectively, as well as extractive measurement of total water content, two tunable diode laser (TDL) hygrometers - APicT and APeT - operating at a wavelength of $1370 \mathrm{~nm}$ are available (Skrotzki, 2012; Skrotzki et al., 2013; Ebert et al., 2005; Fahey et al., 2009). The time resolution of these TDL hygrometers is approximately $1 \mathrm{~s}$ and accuracy is given at $\pm 5 \%$. The in situ water vapor measurement is performed by APicT and the total water content is retrieved by extractive sampling of AIDA gas via a heated stainless steel line to which APeT is connected. From the difference of total water and water vapor measurements, the ice water content IWC within AIDA can be derived. The water partial pressure, $e$, obtained by the TDL instruments can be converted into an ice saturation ratio $S_{\text {ice }}$ by calculating the water vapor saturation pressure, $\hat{e}_{\text {ice }}$, with respect to the AIDA gas temperature, $T_{\mathrm{g}}$ (Murphy and Koop, 2005), ac-

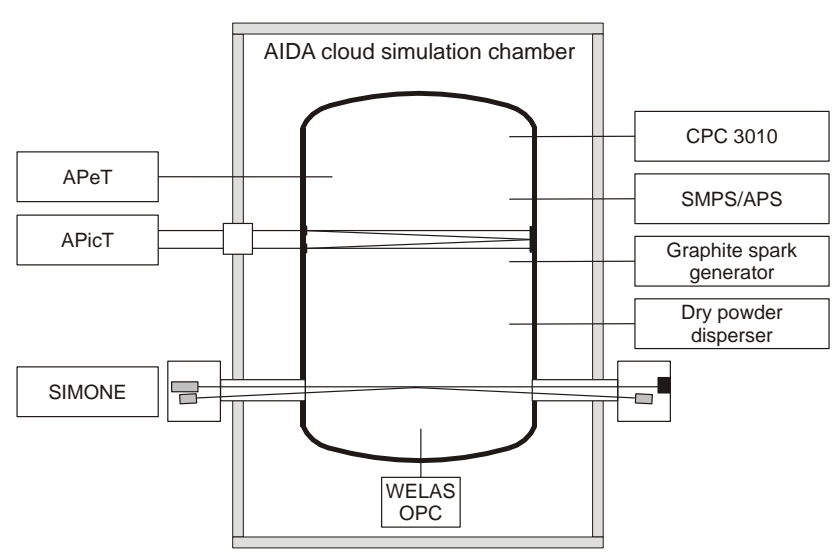

Fig. 1. Schematic drawing of the AIDA cloud chamber with instrumentation for humidity measurements (APicT and APeT), ice particle characterization (SIMONE and WELAS optical particle counter), aerosol generation (graphite spark generator and drypowder disperser), and aerosol characterization (CPC 3010, SMPS, and APS). The gray frame illustrates the thermostated insulating housing surrounding the AIDA chamber

cording to Eq. (5). The accuracy of the retrieval of $S_{\text {ice }}$ is therefore not only determined by the accuracy of the TDL instruments but also by the uncertainty of the gas temperature $T_{\mathrm{g}}$.

\subsubsection{Ice number concentration}

An optical particle counter (OPC; PALAS, WELAS) is available to register ice particle number concentrations, $C_{n}$,ice, for particles in the size range $0.7-40 \mu \mathrm{m}$. This range has been determined for spherical particles with a refractive index of 1.33. The WELAS instrument counts particles by measuring the pulses of white light scattered by individual particles. The instrument is operated at $5 \mathrm{~s}$ time resolution. Its accuracy is estimated to be $\pm 20 \%$ (Möhler et al., 2006).

\subsubsection{In situ laser light scattering}

The in situ light scattering and depolarization instrument SIMONE detects light scattered by aerosol or cloud particles in forward $\left(2^{\circ}\right)$ and backward $\left(178^{\circ}\right)$ direction. It uses a linearly polarized continuous wave semiconductor laser at $488 \mathrm{~nm}$ wavelength. In addition, the parallel and perpendicular polarization components of the backscattered intensity can be detected. Due to its high sensitivity, SIMONE is used to precisely determine the onset of cloud ice particle generation, i.e., the onset of ice nucleation. Further details about the instrument can be found in Schnaiter et al. (2012).

\subsubsection{Aerosol generation}

For injection of aerosol particles into the AIDA chamber, the following aerosol generators have been used: a dry-powder disperser (TSI, model 3433) for the addition of two different 
samples of synthetic hematite particles and a graphite spark generator (PALAS, GFG 1000) which creates soot particles by spark discharge between two electrodes of pure carbon. The obtained GSG soot particles have sizes mainly in the range $100-200 \mathrm{~nm}$ and are agglomerates of individual soot particles with diameters below $10 \mathrm{~nm}$. For details on creation, morphology, and properties of GSG soot, see Möhler et al. (2005) and references therein.

\subsubsection{Aerosol characterization}

The aerosol number concentration, $C_{n, \text { ae }}$, is measured by a condensation particle counter (TSI, CPC 3010) at a time resolution of $1 \mathrm{~s}$. Its accuracy is estimated to be $\pm 20 \%$. Aerosol size distributions are determined by a scanning mobility particle sizer (SMPS, TSI) in combination with an aerodynamic particle sizer (APS, TSI). From these measurements, the median aerosol size $\mu_{\mathrm{ae}}$ and the width parameter $\sigma_{\mathrm{ae}}$ of a lognormal fit to the measured aerosol distribution are estimated to be retrieved with an accuracy of $\pm 10 \%$ and $\pm 15 \%$, respectively; see Sect. 3.2. Aerosol size distribution measurements were carried out close before the start of each AIDA experiment.

Rigorous cleaning by evacuating the AIDA vessel to pressures below $0.1 \mathrm{hPa}$ and purging with synthetic air when changing the aerosol type resulted in very low background concentrations of aerosol particles (typically below $0.1 \mathrm{~cm}^{-1}$ ) before addition of the aerosol. Hematite and GSG soot were used as aerosol particles due to their efficiency as ice nuclei in the temperature range 190-235 K (Gallavardin et al., 2008; Möhler et al., 2005). A second reason for the choice of hematite particles and GSG soot as aerosol was that these aerosol particles are hardly detected by the WELAS OPC due to their small size and low reflectivity, which reduces interference of aerosol particle signals in the ice number concentration measurement to a minimum. This interference is caused by aerosol particles larger in optical diameter than the lower detection limit of the WELAS OPC of $0.7 \mu \mathrm{m}$.

Of the two hematite particle samples used for the experiments, sample one (hematite \#1) consists of nearly spherical particles with a mean diameter of approximately $200 \mathrm{~nm}$, while hematite sample two (hematite \#2) consists of prolate spheroids with an aspect ratio of nearly two with mean major extension of approximately $500 \mathrm{~nm}$. These characteristics of the hematite particles have been determined by scanning electron microscopy (Vragel, 2009). The GSG soot particles have sizes mainly in the range $100-200 \mathrm{~nm}$ as described above. For the size distribution of the aerosol types, an aerosol background in the WELAS OPC measurement of below $1 \mathrm{~cm}^{-3}$ was obtained for GSG soot and hematite \#1 as well as below $10 \mathrm{~cm}^{-3}$ for hematite \#2. In order to subtract this aerosol background from the OPC ice number concentration measurement, a lower cut-off at $1 \mu \mathrm{m}$ particle size was applied to the OPC data for all AIDA experiments.

\subsection{Overview of experiments}

Table 3 gives an overview of the AIDA cirrus cloud experiments carried out for the determination of the ice accommodation coefficient $\alpha_{\text {ice }}$. As mentioned above, they spread a temperature range of approximately $190-235 \mathrm{~K}$ to indicate a potential dependency of $\alpha_{\text {ice }}$ on temperature. A wide variety of maximum ice number concentrations $C_{n}$,ice, between approximately $40 \mathrm{~cm}^{-3}$ and $200 \mathrm{~cm}^{-3}$, and maximum ice saturation ratios $S_{\text {ice }}$, from moderate supersaturations of $16 \%$ up to supersaturations close to the homogeneous freezing threshold of supercooled solution droplets (Koop et al., 2000), were achieved. This variety in $C_{n}$,ice and $S_{\text {ice }}$ was deemed appropriate to demonstrate a potential dependence of $\alpha_{\text {ice }}$ on ice particle size or supersaturation. Conducting the experiments at lower pressures would demonstrate higher sensitivity for the accommodation coefficient of water on the growing ice crystals; however, here we started the expansion experiments at approximately $1 \mathrm{~atm}$. Test experiments at $200 \mathrm{hPa}$ gave lower cooling rates and therefore supersaturations and ice crystal number concentrations were smaller compared to $1 \mathrm{~atm}$. These difficulties compensated the potential gain expected for operating at lower pressures.

Aerosol surface size distributions for two of the AIDA experiments listed in Table 3 are given in Fig. 2. They are obtained from SMPS number size distribution measurements. For the hematite particles, the size distributions are given with respect to their volume-equivalent diameter. A dynamic shape factor of 1.1 was assumed for hematite \#1 and 1.0 for hematite \#2. For GSG soot the size distributions are given with respect to the electrical mobility diameter. Lognormal fits were applied to the experimental aerosol surface size distributions, bimodal for the hematite aerosol consisting of monomers, as well as agglomerates and monomodal for GSG soot. The lognormal functions are described by the median aerosol size $\mu_{\mathrm{ae}}$ and the width parameter $\sigma_{\mathrm{ae}}$. The size distributions show that aerosol particles greater than $1 \mu \mathrm{m}$ are negligible for both aerosol types and confirm the mean aerosol sizes given above.

\section{Modeling methods}

In order to retrieve values for the ice accommodation coefficient $\alpha_{\text {ice }}$ from the AIDA cirrus cloud experiments, experimental data were evaluated with two independent model approaches. The first model used is SIGMA (Simple Ice Growth Model for determining Alpha), the second one is ACPIM (Aerosol-Cloud-Precipitation Interaction Model).

Both models apply Eq. (6) for the parameterization of cirrus ice particle growth and assumed spherical ice particle shape. This implies that ice particle size and mass are connected by

$r_{\mathrm{p}}=\left(\frac{3}{4 \pi} \frac{m_{\mathrm{p}}}{\rho_{\text {ice }}}\right)^{1 / 3}$ 

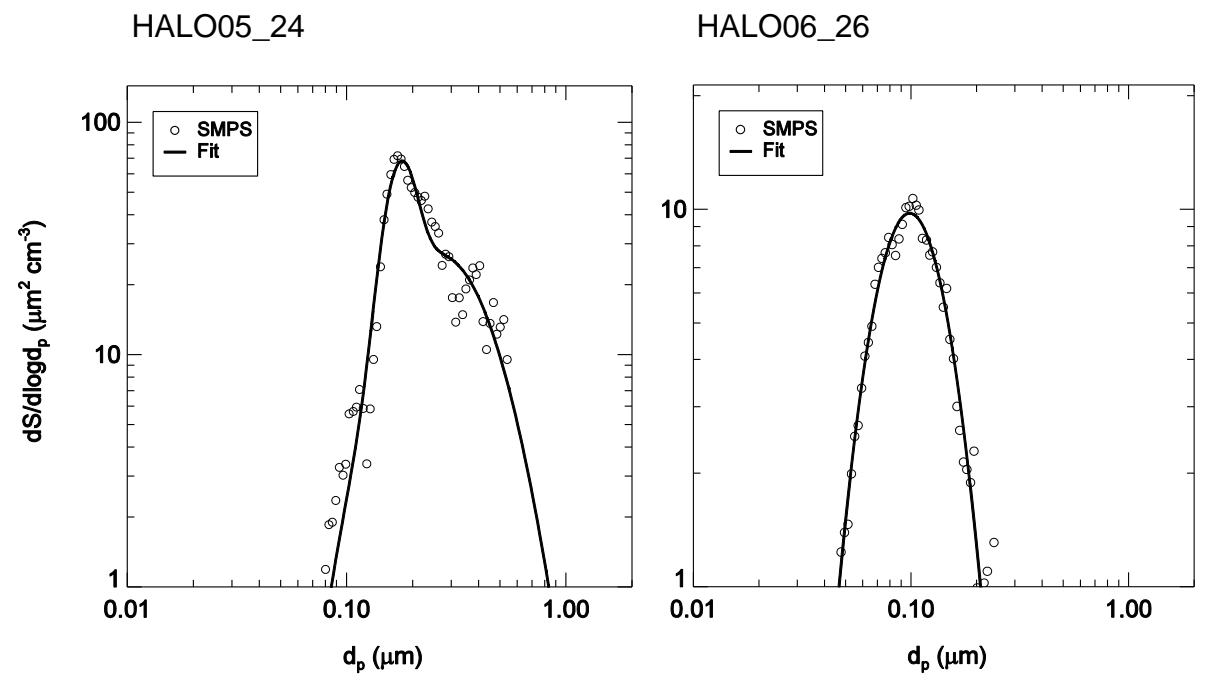

Fig. 2. Aerosol surface size distributions for the experiments HALO05_24 with hematite \#1 aerosol and HALO06_26 with GSG soot aerosol. The surface size distributions are inferred from number size distributions as measured by a scanning mobility particle sizer SMPS. Lognormal fits (solid lines) are applied to the measurement data (open symbols), bimodal for the hematite aerosol (monomers and agglomerates), and monomodal for the graphite spark generator soot aerosol.

Table 3. Overview of AIDA accommodation coefficient experiments sorted by aerosol type and temperature. Two types of aerosols were used: hematite particles (two different samples) and graphite spark generator (GSG) soot. $p\left(t_{0}\right)$ and $T_{\mathrm{g}}\left(t_{0}\right)$ indicate gas pressure and temperature at start time $t_{0}$ of the experiments. The experiments cover a broad temperature range relevant for cirrus clouds (approximately between $190 \mathrm{~K}$ and $235 \mathrm{~K}$ ) and a wide variety of initial aerosol number concentrations $C_{n}$, ae $\left(t_{0}\right)$, maximum ice number concentrations $C_{n}$,ice, and maximally obtained ice saturation ratios $S_{\text {ice }}$.

\begin{tabular}{|c|c|c|c|c|c|c|}
\hline Exp. no. & Aerosol particles & $p\left(t_{0}\right)[\mathrm{hPa}]$ & $T_{\mathrm{g}}\left(t_{0}\right)[\mathrm{K}]$ & $C_{n, \mathrm{ae}}\left(t_{0}\right)\left[\mathrm{cm}^{-3}\right]$ & $\max \left[C_{n, \text { ice }}\right]\left[\mathrm{cm}^{-3}\right]$ & $\max \left[S_{\text {ice }}\right]$ \\
\hline HALO06_19 & Hematite \#1 & 1008.5 & 234.9 & 315 & 111 & 1.23 \\
\hline HALO06_20 & Hematite \#1 & 1011.7 & 234.9 & 192 & 88 & 1.31 \\
\hline HALO06_21 & Hematite \#1 & 1011.3 & 225.0 & 287 & 72 & 1.16 \\
\hline HALO06_22 & Hematite \#1 & 1011.9 & 224.5 & 183 & 61 & 1.24 \\
\hline HALO05_18 & Hematite \#1 & 1009.1 & 213.7 & 189 & 90 & 1.26 \\
\hline HALO04_05 & Hematite \#2 & 995.4 & 212.5 & 280 & 63 & 1.36 \\
\hline HALO05_24 & Hematite \#1 & 1005.7 & 198.1 & 185 & 60 & 1.69 \\
\hline HALO04_09 & Hematite \#2 & 965.9 & 196.4 & -* & 56 & 1.51 \\
\hline HALO06_23 & GSG soot & 1015.3 & 233.9 & 1976 & 153 & 1.30 \\
\hline HALO06_24 & GSG soot & 1015.9 & 234.0 & 862 & 121 & 1.33 \\
\hline HALO06_25 & GSG soot & 1015.5 & 224.3 & 321 & 72 & 1.27 \\
\hline HALO06_26 & GSG soot & 1015.3 & 223.7 & 164 & 65 & 1.30 \\
\hline HALO06_27 & GSG soot & 1019.7 & 212.8 & 269 & 80 & 1.45 \\
\hline HALO06_28 & GSG soot & 1019.9 & 213.0 & 145 & 37 & 1.41 \\
\hline HALO04_26 & GSG soot & 1011.4 & 198.2 & 2410 & 197 & 1.37 \\
\hline
\end{tabular}

* no measurement available

where $\rho_{\text {ice }}$ is the mass density of ice. The assumption of spherical ice particles also implies that no exposed facets of enhanced growth (Libbrecht, 2005) exist.

The assumption of spherical ice particles is justified since ice particles smaller than $20 \mu \mathrm{m}$ in diameter have been observed to be compact and nearly spherical in cirrus cloud measurements (Korolev and Isaac, 2003; Mitchell et al., 2011) as well as in laboratory studies (Abdelmonem et al.,
2011; Earle et al., 2010) for temperatures below $-35^{\circ} \mathrm{C}$. The maximum size to which the ice particles in all experiments listed in Table 3 grew stayed below $20 \mu \mathrm{m}$.

Furthermore, the analysis of SIMONE depolarization ratio data for HALO06_25 and HALO06_27 as well as two AIDA ice nucleation experiments with GSG soot at approximately $200 \mathrm{~K}$ shows that prolate spheroids with a maximum aspect ratio of two represent the entire ensemble of ice particles 
present in these experiments well, cf. Schnaiter et al. (2012). These results refer to a temperature range approximately between $200 \mathrm{~K}$ and $225 \mathrm{~K}$ and can be used to estimate an upper bound for the error resulting from the assumption of spherical particles. Spheroids with an aspect ratio of two result in a deviation of $4 \%$ in ice particle capacitance $C_{\mathrm{s}}$ (McDonald, 1963) compared to the capacitance $r_{\mathrm{p}}$ of a volume-equivalent sphere. The ice particle shape cannot be excluded as being hexagonal columnar for a fraction of the ice particles in the entire ensemble, but even in this case the capacitance $C_{\mathrm{h}}$ (Westbrook et al., 2008; Westbrook and Heymsfield, 2011) for an aspect ratio of two would not deviate more than $11 \%$ from $r_{\mathrm{p}}$ of a volume-equivalent sphere. Therefore, it is expected that the assumption of spherical ice particles does not have significant impact on the retrieval of the accommodation coefficient $\alpha_{\text {ice }}$.

Model specific details about SIGMA and APCIM and their application to the AIDA cirrus cloud experiments are now given.

\subsection{SIGMA}

The ice growth model SIGMA has been developed as a dedicated tool to model the growth of cirrus cloud ice particles dependent on the magnitude of the accommodation coefficient $\alpha_{\text {ice }}$. A list of all physical quantities used in SIGMA is given in Appendix B.

SIGMA relies on the Dahneke approach (Dahneke, 1983) for a choice of the vapor jump length $\Delta_{\mathrm{V}}$ in Eq. (3). This approach sets

$\Delta_{\mathrm{v}}=\lambda_{\mathrm{w}}$,

where the mean free path $\lambda_{\mathrm{w}}$ is connected to the diffusivity $D_{\text {w }}$ by

$\lambda_{\mathrm{w}}=\frac{2 D_{\mathrm{w}}}{\bar{c}_{\mathrm{w}}}$.

As output quantity, SIGMA calculates the time-dependent

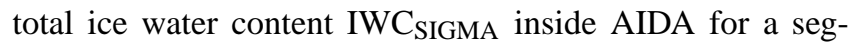
mentation of ice particle growth into individual bins. Each individual bin is indexed by $i$ and has a different start time of ice growth $t_{i}$. This is illustrated in Fig. 3. Of a total number of ice growth bins $N$, a fraction $n(t)$ is active at time $t$. Each bin contains ice particles of mass $m_{\mathrm{p}}[i]$ with ice number concentration $C_{n \text {,ice }}[i]$. By summing over all active bins SIGMA calculates IWC $_{\text {SIGMA }}$ in terms of volume mixing ratio by the following relation:

$\operatorname{IWC}_{\text {SIGMA }}=\frac{R T_{\mathrm{g}}}{M_{\mathrm{w}} p} \sum_{i=1}^{n(t) \leq N} C_{n, \text { ice }}[i] m_{\mathrm{p}}[i]$,

where $m_{\mathrm{p}}[i]$ is obtained by the integration of Eq. (6)

$m_{\mathrm{p}}[i]=\int_{t_{i}}^{t} \frac{\mathrm{d} m_{\mathrm{p}}}{\mathrm{d} t} \Delta t$.

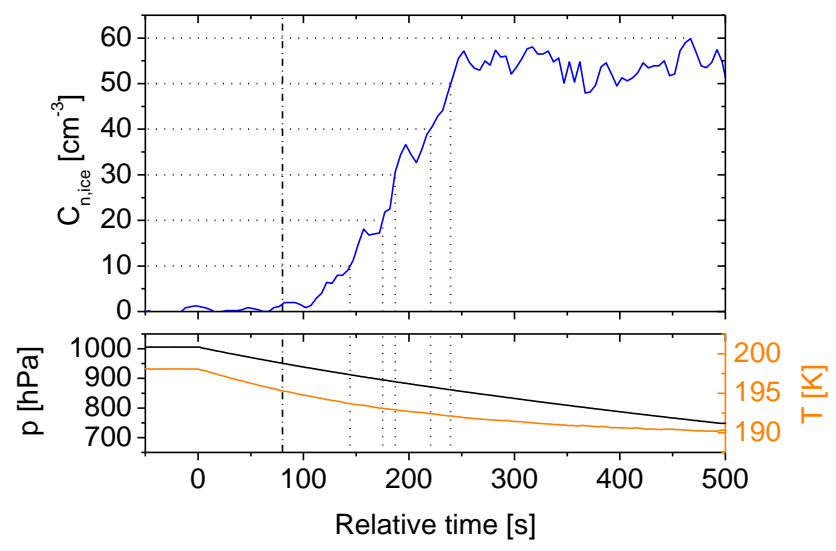

Fig. 3. Division of ice particle growth into individual bins in SIGMA. The blue line shows a typical evolution of the ice number concentration $C_{n}$,ice during an AIDA expansion experiment as measured by the WELAS optical particle counter. Ice onset is indicated by the dashed dotted line and is chosen as start time $t_{1}$ for ice growth in the first ice growth bin. Equidistant division of $C_{n}$,ice with respect to the maximally reached ice number concentration yields the ice growth start times $t_{i}$ in the subsequent ice growth bins (dotted lines).

The time-dependent total ice number concentration $C_{n \text {,ice, }}$ the gas pressure $p$, and the gas temperature $T_{\mathrm{g}}$ are SIGMA input parameters along with the ice saturation ratio $S_{\text {ice }}$ of water vapor which is required in Eq. (6). These measured quantities are linearly interpolated to match the model time resolution $\Delta t$.

For the application of SIGMA to the AIDA experiments listed in Table 3, the calculation of IWC SIGMA $_{\text {covered time }}$ spans approximately between $100 \mathrm{~s}$ and $500 \mathrm{~s}$ with a time resolution $\Delta t=0.1 \mathrm{~s}$. Ice particle growth was segmented into $N=20$ individual size bins with the initial diameter of the ice particles in each ice growth bin set to $1 \mu \mathrm{m}$, which corresponds to the cut-off set to safely separate between the WELAS OPC counts for aerosol and ice particles.

\subsection{ACPIM}

The Aerosol-Cloud-Precipitation Interaction Model has been described and used for nucleation studies in the AIDA by Connolly et al. (2009). More thorough and up-to-date descriptions of the numerical methods used are provided by Dearden et al. (2011) and Connolly et al. (2012). Essentially, it is run as a bin-microphysical parcel model in which the aerosol size distribution is discretized over a bin grid and the growth of ice particles and interaction with the temperature and water vapor field are solved as a coupled set of ordinary differential equations. In this paper only the process of growth of ice by vapor deposition was considered. ACPIM was constrained to the measurements of temperature, pressure, total water, and ice particle number concentration, 
while the humidity is allowed to vary and depends on the growth of the ice by vapor deposition.

In each model time step, the rate of change of temperature was specified so that it equaled the measured value during the experiment. The ice crystals are assumed to grow from the aerosol size distribution as ice is nucleated on the aerosol particles and form at a rate that was measured using the WELAS OPC. An assumption was that ice nucleation occurred in proportion to the surface area of the aerosol particles so that the largest particles have the highest chance of nucleating ice; this was found to be the case in other similar experiments (Saunders et al., 2010). Once an aerosol particle has nucleated ice it is no longer available to nucleate further ice. The ice particles then grow by vapor deposition, depleting the available water vapor; however, an additional term is also added to the modeled humidity for each time step so that the total water content in the model equals that which was measured throughout the experiment. A comparison of the modeled and measured humidity then allows for an assessment of the level of agreement between model and data.

\section{Experimental and modeling data}

Combined measurement and model data based on the description of Sects. 3 and 4 for the AIDA experiments HALO05_24 with hematite aerosol and HALO06_26 with GSG soot aerosol are presented in Fig. 4. Experimental data of the ice water content IWC are compared with the SIGMA modeled ice water content IWC SIGMA $_{\text {for different values of }}$ the accommodation coefficient $\alpha_{\text {ice }}$. Correspondingly, independent ACPIM calculations of the temporal evolution of ice saturation ratio $S_{\text {ice }}$ for different values of $\alpha_{\text {ice }}$ are presented together with the according measurement data. For both experiments, SIGMA as well as ACPIM suggest $\alpha_{\text {ice }}>0.1$ and are in good agreement with respect to each other despite their different approaches to retrieve $\alpha_{\text {ice }}$.

Note that here and for all other experiments listed in Table 3, a constant offset correction was applied to the experimental data set of APeT total water content in order to match it with the APicT water vapor content at ice onset of each experiment. This approach assumes that the IWC inside AIDA is zero until the onset of ice nucleation. The necessity of this correction by up to $7 \%$ for $T_{\mathrm{g}}<200 \mathrm{~K}$ may be because of the APeT extractive sampling at one point inside the AIDA chamber close to the vessel wall, which may be influenced by slight gas heterogeneities inside AIDA during the dynamic expansions. This could cause deviations when compared to the APicT water vapor measurement, which is more representative of humidity conditions along the entire diameter of the chamber.

\section{Uncertainty analysis}

From the SIGMA and ACPIM model calculations, a best-fit value for the accommodation coefficient with an uncertainty on this best-fit value is obtained for each AIDA experiment. This is done by means of an uncertainty analysis based on the Monte Carlo method (Rubinstein and Kroese, 2008).

The Monte Carlo method was implemented in the following manner, cf. Cullen and Frey (1999). For each run of the Monte Carlo simulation, SIGMA and ACPIM input data sets as well as the experimentally determined data set to which the model output is compared are randomly varied according to their accuracy. Note that, in general, the measurement precision is of minor importance for the measurement uncertainty and therefore not taken into account. Uncertainties of gas pressure $p$ with $\pm 1 \mathrm{hPa}$ and gas temperature $T_{\mathrm{g}}$ with $\pm 0.3 \mathrm{~K}$ (Möhler et al., 2006) are expected to be insignificant and are neglected as well.

Although uncertainties in thermophysical quantities like diffusion coefficients (see Sect. 2) or latent heat (see Appendix A) contribute to the overall uncertainty for the accommodation coefficients (for example in the experimental configuration of Miles et al., 2012), we refrain from including them in this systematic uncertainty analysis since the dominating factors for our work are uncertainties in the experimental observables.

The probability density functions used for the variation are, in the case of SIGMA, normal distributions with a standard deviation corresponding to the respective measurement accuracy. In the case of ACPIM, these functions are given by even probability distributions within the interval defined by the measurement accuracy, which gives a more conservative error bar on the final output. The accuracies taken as basis for the uncertainty analysis are given in Table 4 and are based on the measurement accuracies discussed in Sect. 3.1. As $S_{\text {ice }}$ and IWC are not retrieved from independent measurements, the variation of these two quantities is coupled. For ACPIM, it does not make sense to adjust the total water measurement by its accuracy since conditions were close to ice saturation at the start of the experiments.

In the case of SIGMA, the Monte Carlo simulation consists of 1000 model runs for each AIDA experiment. For the randomly varied data sets of each run, the SIGMA model obtains a best-fit value $\alpha_{\text {ice }}^{*}$ by comparing the model output IWC $_{\text {SIGMA }}$ to the experimentally determined IWC. This is done by means of a Levenberg-Marquardt fitting algorithm (Marquardt, 1963; Press et al., 2007) which varies $\alpha_{\text {ice }}$ until a best-fit value $\alpha_{\text {ice }}^{*}$ resulting in optimal agreement between IWC SIGMA and experimental IWC is obtained. The fitting algorithm is constrained to $\alpha_{\text {ice }}^{*} \leq 1$ in this procedure as $\alpha_{\text {ice }}^{*}>1$ does not represent a physically plausible state. The resulting distribution of $1000 \alpha_{\text {ice }}^{*}$ values allows computing of an overall best-fit value with uncertainty bounds for each AIDA experiment. The overall best-fit value is given by the median, its lower bound by the lower quartile, and its upper bound by the upper quartile of the $\alpha_{\mathrm{ice}}^{*}$ distribution.

In the case of ACPIM, simulations for 13 of the 15 experiments given in Table 3 were considered, and for each of them 100 model runs with different values of the input 
HALO05_24
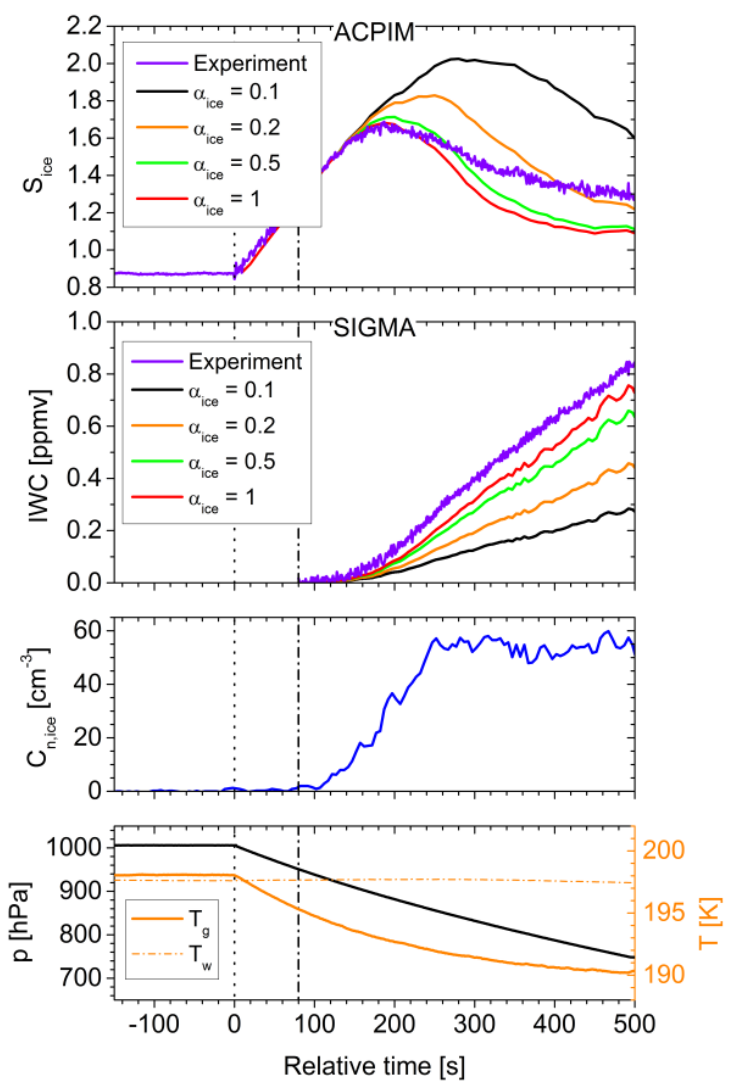

HALO06_26
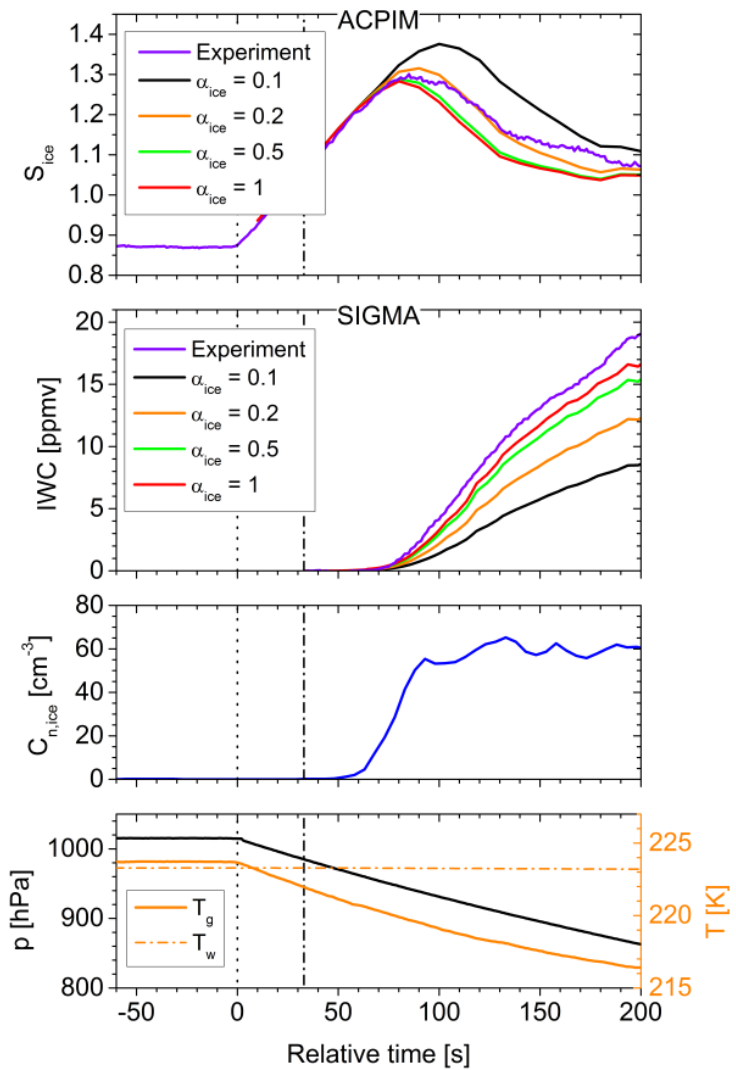

Fig. 4. Experimental measurements and model calculations for one experiment with hematite aerosol at low temperatures (HALO05_18) and one experiment with graphite spark generator soot aerosol at intermediate temperatures (HALO06_26). The aerosol surface size distributions for these experiments are given in Fig. 2. Panels from top to bottom show ice saturation ratio $S_{\text {ice }}$ derived from APicT water vapor content, ice water content IWC inferred from APicT water vapor and APeT total water measurement, ice number concentration $C_{n}$,ice measured by the WELAS optical particle counter as well as gas pressure $p$, gas temperature $T_{\mathrm{g}}$, and AIDA wall temperature $T_{\mathrm{W}}$. For a range of accommodation coefficients $\alpha_{\text {ice }}$, results from the SIGMA model IWC SIGMA for the evolution of ice water content and from the ACPIM model for the evolution of $S_{\text {ice }}$ are included in the respective panels. The dotted line indicates the start time of the experiment, i.e., the start of pumping, while the dashed dotted line depicts the ice onset time inferred from SIMONE forward scattering data.

parameters were performed with seven different values of the ice accommodation coefficient: $\alpha_{\text {ice }}=0.01,0.02,0.05,0.1$, $0.2,0.5$, and 1.0. This made a grand total of 9100 ACPIM simulations. For each run we then calculated the sum of the squares of the residual between the measured humidity and the model for $600 \mathrm{~s}$ of the experiment (see Fig. 5a). In order to ensure that the Monte Carlo simulation was unbiased, we generated a vector of values of $\alpha_{\text {ice }}$ on an equidistant spaced grid, and the residuals at values of $\alpha_{\text {ice }}$ that were not modeled were estimated by linear interpolation (which was reasonable in this case as there was a smooth variation of the sum of squares with $\alpha_{\text {ice }}$ ). This gives a large distribution of the sum of squares (e.g., Fig. 5b).

To find the values of $\alpha_{\text {ice }}$ that gave the lowest sums of squares residuals, we took the sums of squares of residuals for each experiment and created a histogram with 30 logarithmically spaced bins, following which we calculated the
Table 4. Accuracies of the experimental data sets used for the SIGMA and ACPIM model uncertainty analysis based on the Monte Carlo method. The points mark if the data set is randomly varied in the uncertainty analysis of the respective model.

\begin{tabular}{llcc}
\hline & Accuracy & SIGMA & ACPIM \\
\hline$S_{\text {ice water vapor }}$ & $\pm 5 \%$ & $\bullet$ & \\
Ice water content IWC & $\pm 5 \%$ & $\bullet$ & \\
Ice number concentration $C_{n, \text { ice }}$ & $\pm 20 \%$ & $\bullet$ & $\bullet$ \\
Aerosol number concentration $C_{n, \text { ae }}$ & $\pm 20 \%$ & & $\bullet$ \\
Median aerosol size $\mu_{\mathrm{ae}}$ & $\pm 10 \%$ & & $\bullet$ \\
Aerosol width parameter $\sigma_{\mathrm{ae}}$ & $\pm 15 \%$ & & $\bullet$ \\
\hline
\end{tabular}

cumulative fraction histogram of the sums of squares of the residuals (e.g., Fig. 5c). We then found the bin which had a cumulative fraction larger than 0.75 , which was defined as the critical value of sums of squares above which we 


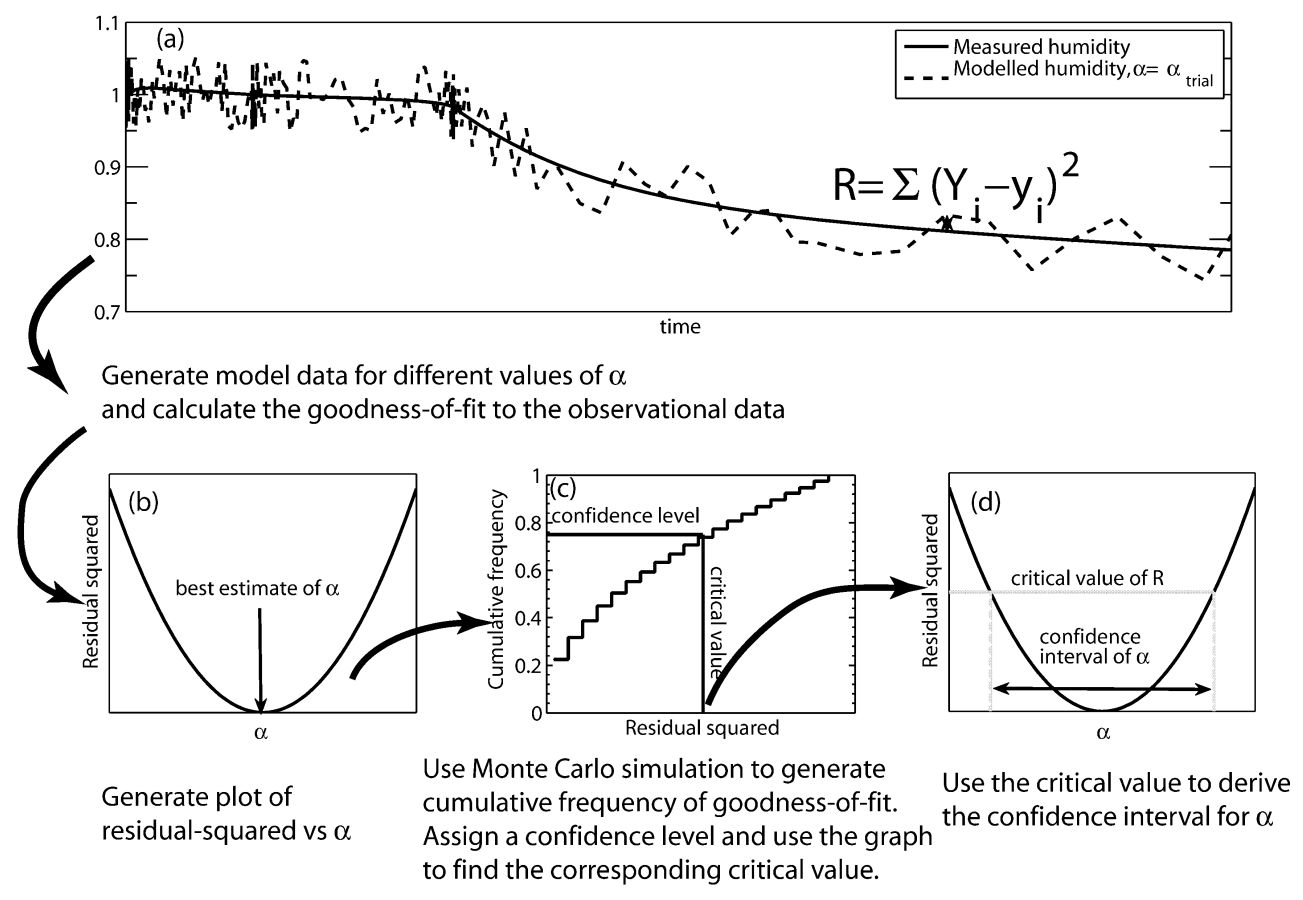

Fig. 5. A schematic of the technique used to find the best guess and confidence interval of the ice accommodation coefficient $\alpha_{\text {ice }}$ using ACPIM. Panel (a) shows a schematic of the observed and model-calculated relative humidity for one choice of $\alpha_{\text {ice }}$. The sum of squares of the residual is calculated for each 10 second time interval of the experiment from 0 to $600 \mathrm{~s}$. This is done for different values of $\alpha_{\text {ice }}$, so that a graph of the sum of squares vs. $\alpha_{\text {ice }}$ can be produced (b). A Monte Carlo simulation is used to generate the cumulative fraction of residuals (c) and then a significance level for the error bar is assigned (25\%) to find the critical value of the residual above which the observation and model are deemed to be significantly different. Remapping this to find the corresponding $\alpha_{\text {ice }}$ gives the confidence interval for alpha (d).

specified there to be poor agreement between model and data. To find the value of $\alpha_{\text {ice }}$ that this corresponds to, we used the data indices to find all of the $\alpha_{\text {ice }}$ values above this point; the minimum value of those $\alpha_{\text {ice }}$ corresponds to the lower quartile and the maximum to the upper quartile (e.g., Fig. 5d). To find the median we did the same procedure except used a cumulative fraction of 0.5 (Fig. 5d).

Note that in the case of SIGMA, the given accuracy for the measurement of water vapor $S_{\text {ice }}$ is the factor dominating the obtained uncertainty limits except for the experiments at lowest temperatures around $200 \mathrm{~K}$ for which uncertainty of the ice number concentration $C_{n}$,ice starts to become equally important. The contribution of IWC accuracy is of minor importance for all experiments. For ACPIM, uncertainties in aerosol size distribution parameters and ice number concentrations tend to have the largest effect on the sum of squares of residuals.

\section{Results and discussion}

For the fifteen AIDA cirrus cloud experiments covering a temperature range between $190 \mathrm{~K}$ and $235 \mathrm{~K}$ (see Table 3), overall best-fit values of the ice accommodation coefficient $\alpha_{\text {ice }}$ along with uncertainty bounds have been obtained by
SIGMA and ACPIM according to Sect. 5.1. The results are presented in Fig. 6. For all individual experiments, $\alpha_{\text {ice }}>0.2$ is preferred by both models and $\alpha_{\text {ice }}<0.1$ is excluded by the respective uncertainty bounds. ACPIM seems to prefer lower $\alpha_{\text {ice }}$ values with increasing temperature, but no significant temperature dependence of $\alpha_{\text {ice }}$ can be observed in the ACPIM and SIGMA results. Therefore, average values of $\alpha_{\text {ice }}$ valid for the given temperature range are computed to be $\alpha_{\text {ice }}^{\text {SIGMA }}=0.9_{-0.5}^{+0.1}$ and $\alpha_{\text {ice }}^{\text {ACPIM }}=0.5_{-0.3}^{+0.5}$. In addition, no indication for a dependence of $\alpha_{\text {ice }}$ on ice particle size or on supersaturation has been found for the considered ice particles smaller than $20 \mu \mathrm{m}$ and supersaturations of up to $70 \%$.

ACPIM results in a somewhat lower value for $\alpha_{\text {ice }}$ than SIGMA, but within the uncertainty limits SIGMA and ACPIM results are in good agreement with respect to each other. Therefore, the results of both models are combined to one overall result: $\alpha_{\text {ice }}=0.7_{-0.5}^{+0.3}$. A comparison of this overall result with existing literature data is depicted in Fig. 7. The given literature values are based on laboratory measurements of $\alpha_{\text {ice }}$ (cf. Table 1) and cirrus cloud model studies (cf. Table 2).

Classification of the presented results with respect to previous cirrus cloud model studies generally shows good agreement. A possible source of uncertainty in the model studies 

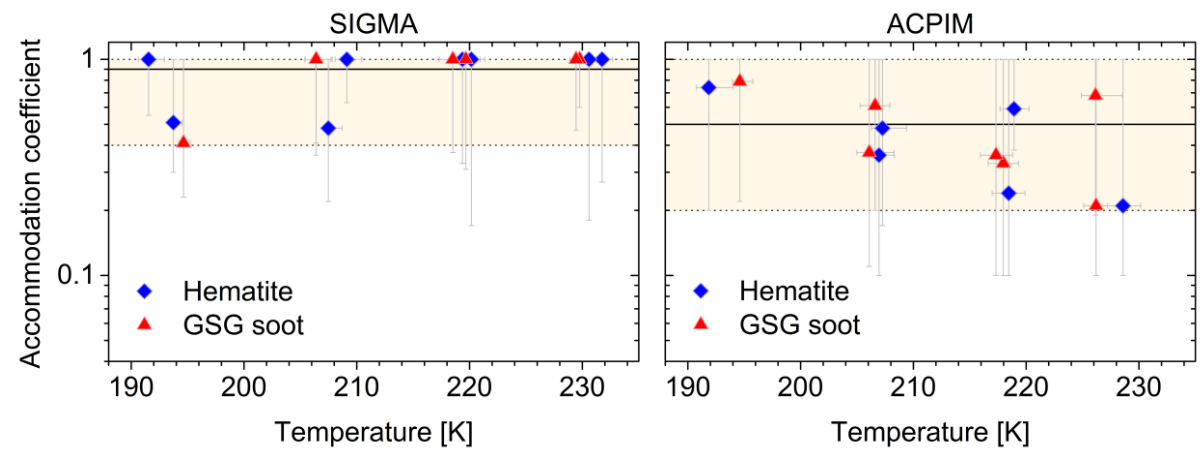

Fig. 6. Accommodation coefficients $\alpha_{\text {ice }}$ obtained from SIGMA and ACPIM model calculations for the AIDA experiments listed in Table 3. Best-fit values relate to the median of the distributions of $\alpha_{\text {ice }}$ values that were retrieved by the uncertainty analysis described in Sect. 5.1, while error bars indicate the respective lower and upper quartiles. Likewise, median as well as lower and upper quartiles were determined from the temperature distribution of each experiment and applied accordingly. The temperature-averaged $\alpha_{\text {ice }}$ values obtained by SIGMA $\alpha_{\text {ice }}^{\text {SIGMA }}=0.9_{-0.5}^{+0.1}$ and ACPIM $\alpha_{\text {ice }}^{\text {ACPIM }}=0.5_{-0.3}^{+0.5}$ are given by the solid black lines with the shaded region indicating their uncertainty.
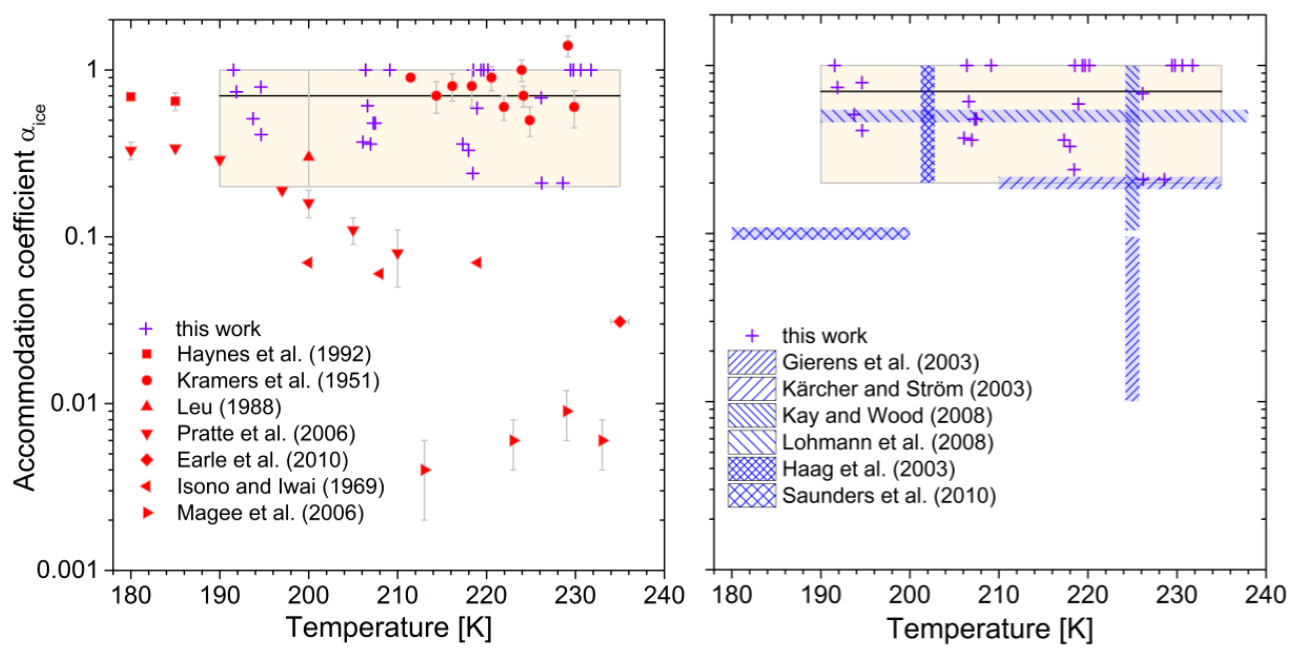

Fig. 7. Comparison of the combined SIGMA and ACPIM result $\alpha_{\text {ice }}=0.7_{-0.5}^{+0.3}$ (black solid line, uncertainty illustrated by the shaded region) resulting from the AIDA cirrus cloud experiments (purple crosses, cf. Fig. 6) between $190 \mathrm{~K}$ and $235 \mathrm{~K}$ with literature data from laboratory measurements (red symbols, cf. Table 1) and cirrus cloud model studies (blue bars, cf. Table 2). Error bars are included when given in the

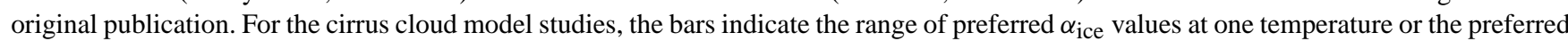
$\alpha_{\text {ice }}$ value within the considered temperature range, respectively.

relying on atmospheric in situ cirrus cloud data is the measurement of ice particle number concentrations which could yield artificially enhanced number concentrations due to shattering of cloud ice particles (Field et al., 2003; McFarquhar et al., 2007). This enhanced ice number concentrations would result in an underestimated $\alpha_{\text {ice. }}$. However, this explanation does possibly not apply to the study by Gierens et al. (2003) in which $0.01<\alpha_{\text {ice }}<0.1$ was preferred. Gayet et al. (2006) argued that shattering of cloud ice particles can probably be excluded for the field measurement data on which the analysis by Gierens et al. (2003) is based.

Discrepancies of the result $\alpha_{\text {ice }}=0.7_{-0.5}^{+0.3}$ compared to laboratory measurements of $\alpha_{\text {ice }}$ are in part significant. Magee et al. (2006) obtained the result $0.004 \pm 0.002<\alpha_{\text {ice }}<0.009 \pm$
0.003; Earle et al. (2010) and Isono and Iwai (1969) retrieved $\alpha_{\text {ice }}$ values in the $10^{-2}$ range. A possible explanation for the very low values of $\alpha_{\text {ice }}$ obtained by these experiments could be the systematic underestimation of the ice saturation ratio $S_{\text {ice }}$ of water vapor. It has been pointed out in Sect. 5.1 that the uncertainty in the measurement of $S_{\text {ice }}$ usually is the dominant source for uncertainty in the retrieval of $\alpha_{\text {ice. }}$. An accuracy for $S_{\text {ice }}$ of $5 \%$ is given in Magee et al. (2006) albeit $S_{\text {ice }}$ is not directly measured in the region of ice particle growth but inferred from the amount of water vapor emitted from a water source into the experimental apparatus. Admittedly, it is argued that the humidity is calibrated using known growth factors for ammonium sulphate particles. However, it is not clear in Magee's study whether these calibrations 
were at temperatures above $0{ }^{\circ} \mathrm{C}$. In this case, frost built up on the inside of the experimental apparatus during the $\alpha_{\text {ice }}$ measurements may act as an unconsidered sink of water vapor and result in lower ice saturation ratios in the vicinity of the ice particles.

If the given accuracy is assumed to be correct, it translates into a minimum uncertainty of $25 \%$ in supersaturation with respect to ice $\left(S_{\text {ice }}-1\right)$ since maximally obtained $S_{\text {ice }}$ in Magee et al. (2006) is around 1.2. Moreover, the initial size from which the ice particles in Magee et al. (2006) start to grow is above $6 \mu \mathrm{m}$ at nearly ambient pressure conditions. Compared to the size of $0.7 \mu \mathrm{m}$ from which ice growth is observable in our work, this should result in a rather low sensitivity with respect to $\alpha_{\text {ice }}$. According to individual estimates, this low sensitivity combined with the uncertainty in $S_{\text {ice }}$ would allow for $\alpha_{\text {ice }}$ values greater than $10^{-2}$. If the given uncertainty in $S_{\text {ice }}$ has been estimated too low, e.g., if water vapor losses to the wall of the experimental apparatus have been evaluated incorrectly, even much higher values of $\alpha_{\text {ice }}>0.1$ could possibly not be excluded by the experiments of Magee et al. (2006). Therefore, this we feel highlights the importance of in situ measurements of water vapor when attempting to quantify the ice accommodation coefficient.

\section{Conclusions}

Dedicated experiments at the aerosol and cloud chamber AIDA were carried out to determine the accommodation coefficient of water molecules on growing cirrus ice particles, $\alpha_{\text {ice }}$, in the temperature range between $190 \mathrm{~K}$ and $235 \mathrm{~K}$. Previous literature values of $\alpha_{\text {ice }}$ cover a range of almost three orders of magnitude in this temperature regime. Therefore, it is difficult to assess the impact of $\alpha_{\text {ice }}$ on growth rates of ice particles in cirrus clouds, and consequently on ice particle properties, number concentrations, and cirrus cloud radiative forcing. The experiments were conducted for a range of atmospheric conditions under which cirrus clouds typically form - including cooling rates and water vapor supersaturations. This resulted in realistic cirrus ice particle growth conditions yielding representative particle sizes and shapes.

The data sets of the performed AIDA experiments were independently evaluated by two different models - SIGMA and ACPIM. With these models it was possible to retrieve a bestfit value for the ice accommodation coefficient $\alpha_{\text {ice }}$ along with uncertainty bounds for each individual experiment. No significant temperature dependence of $\alpha_{\text {ice }}$ was observed. The temperature-averaged value resulting from the SIGMA model is $\alpha_{\text {ice }}^{\text {SIGMA }}=0.9_{-0.5}^{+0.1}$. This result is in good agreement with the independent analysis by the ACPIM model yielding $\alpha_{\text {ice }}^{\text {ACPIM }}=0.5_{-0.3}^{+0.5}$. The combined result of both models, $\alpha_{\text {ice }}=0.7_{-0.5}^{+0.3}$, compares well with most of the previous model studies of cirrus ice particle growth in the atmosphere or in cloud chambers. There are, however, significant discrepancies with respect to three relevant laboratory retrievals of $\alpha_{\text {ice }}$ (Magee et al., 2006; Earle et al., 2010; Isono and Iwai, 1969). The reason for these discrepancies can only be speculated upon at present.

The results of this work suggest that the ice particle growth in cirrus clouds is not significantly impeded as it would be for a low value of the ice accommodation coefficient $\alpha_{\text {ice }}<0.1$. An $\alpha_{\text {ice }}$ value close to unity also suggests that enhanced growth at few specific ice particle facets does not significantly influence the observed ice particle growth that is governed by $\alpha_{\text {ice }}$, i.e., up to a particle size of a few microns. Implications of $\alpha_{\text {ice }}$ for cirrus clouds and their characteristics should therefore be minor. Furthermore, the result $\alpha_{\text {ice }}=0.7_{-0.5}^{+0.3}$ is in good agreement with typical choices for $\alpha_{\text {ice }}$ in cirrus cloud modeling which lie in the range $0.2-1$. Impact on prior calculations of cirrus cloud properties, e.g., in climate or regional models, is thus expected to be negligible and future cirrus model studies can rely on a wellconstrained ice accommodation coefficient.

\section{Appendix A}

\section{Effect of latent heat of deposition}

When the release of latent heat from deposition of water molecules on the surface of an ice particle plays a significant role, the ice particle surface temperature $T_{\mathrm{S}}$ is higher than the temperature $T_{\mathrm{g}}$ of the surrounding air. This results in an inhibition of ice particle growth. The determining parameter in this context is the heat conductivity of air $k_{\mathrm{a}}$. As for the diffusivity $D_{\mathrm{w}}, k_{\mathrm{a}}$ has to be modified for gas kinetic effects which reduce the magnitude of $k_{\mathrm{a}}$ for small ice particle sizes $r_{\mathrm{p}}$, cf. Eq. (3). The modified heat conductivity, $k_{\mathrm{a}}^{*}$, is given by (Pruppacher and Klett, 1997; Eqs. 13-20)

$$
\frac{k_{\mathrm{a}}^{*}}{k_{\mathrm{a}}}=\frac{1}{1+\frac{4 k_{\mathrm{a}}}{\alpha_{\mathrm{T}} r_{\mathrm{p}} \rho_{\mathrm{a}} c_{p, \mathrm{a}} \bar{c}_{\mathrm{w}}}},
$$

where $\alpha_{\mathrm{T}}$ is the thermal accommodation coefficient, $\rho_{\mathrm{a}}$ the density of air, $c_{p, \text { a }}$ the specific heat of air, and $\bar{c}_{\mathrm{w}}$ the mean thermal speed of air molecules corresponding to Eq. (4). The thermal jump distance $\Delta_{\mathrm{T}}$ was set to zero according to Fukuta and Walter (1970). As choice for $\alpha_{\mathrm{T}}$, experimental results suggest a value of unity (Mozurkewich, 1986).

Taking the effect of latent heat release into account yields for the latent heat term $\mathrm{LH}$ in Eq. (6)

$\mathrm{LH}=\frac{L_{\mathrm{s}}}{k_{\mathrm{a}}^{*} T_{\mathrm{g}}}\left(\frac{L_{\mathrm{s}} M_{\mathrm{w}}}{R T_{\mathrm{g}}}-1\right)$.

Inserting the quantities given in Appendix B yields an impact of $\mathrm{LH}$ on the result of Eq. (6) of approximately $5 \%$ at a temperature $T_{\mathrm{g}}=235 \mathrm{~K}$. 


\section{Appendix B}

Table B1. Physical quantities used in SIGMA.

\begin{tabular}{ll}
\hline$\alpha_{\mathrm{T}}=1$ & Mozurkewich (1986) \\
$c_{p, \mathrm{a}}=1.005 \mathrm{~J} \mathrm{~g}^{-1} \mathrm{~K}^{-1}$ & Weast et al. (1987) \\
$D_{\mathrm{w}, 0}=0.211 \mathrm{~cm}^{2} \mathrm{~s}^{-1}$ & Hall and Pruppacher (1976) \\
$\gamma=1.94$ & Hall and Pruppacher (1976) \\
$k_{\mathrm{a}}=\left(5.69+0.0168 T\left({ }^{\circ} \mathrm{C}\right)\right) \times 10^{-5} \mathrm{cal} \mathrm{cm}^{-1} \mathrm{~s}^{-1} \mathrm{~K}^{-1}$ & Beard and Pruppacher (1971) \\
$L_{\mathrm{s}}=2836 \mathrm{~J} \mathrm{~g}^{-1}$ for $190 \mathrm{~K}<T<273 \mathrm{~K}$ & Feistel and Wagner (2007) \\
$M_{\mathrm{a}}=28.964 \mathrm{~g} \mathrm{~mole}^{-1}$ & Weast et al. (1987) \\
$M_{\mathrm{w}}=18.015 \mathrm{~g} \mathrm{~mole}^{-1}$ & Weast et al. (1987) \\
$R=8.314 \mathrm{~J}\left(\mathrm{~mole}^{-1} \mathrm{~K}^{-1}\right)$ & Weast et al. $(1987)$ \\
$\rho_{\mathrm{ice}}=\left(0.9167-1.75 \times 10-4 T\left({ }^{\circ} \mathrm{C}\right)-5.0 \times 10-7 T^{2}\left({ }^{\circ} \mathrm{C}\right)^{2}\right) \mathrm{g} \mathrm{cm}^{-3}$ & \\
\hline
\end{tabular}

Acknowledgements. Skillful support by the AIDA technician team is gratefully acknowledged. This work was supported by the Helmholtz Association through the Virtual Institute on AerosolCloud Interactions (VI-ACI) [VH-VI-233] and the President's Initiative and Networking Fund. P. Connolly acknowledges support from the NERC ACID-PRUF (Aerosol-Cloud Interactions - A Directed Programme to Reduce Uncertainty in Forcing through a Targeted Laboratory and Modelling Programme) consortium [grant code NE/I020121/1]. The publication of this work was funded by the European Geosciences Union through an EGU OSP award.

Edited by: S. Buehler

\section{References}

Abdelmonem, A., Schnaiter, M., Amsler, P., Hesse, E., Meyer, J., and Leisner, T.: First correlated measurements of the shape and light scattering properties of cloud particles using the new Particle Habit Imaging and Polar Scattering (PHIPS) probe, Atmos. Meas. Tech., 4, 2125-2142, doi:10.5194/amt-4-2125-2011, 2011.

Beard, K. V. and Pruppacher, H. R.: A Wind Tunnel Investigation of the Rate of Evaporation of Small Water Drops Falling at Terminal Velocity in Air, J. Atmos. Sci., 28, 1455-1464, doi:10.1175/1520-0469(1971)028<1455:AWTIOT > 2.0.CO;2, 1971.

Choularton, T. W. and Latham, J.: Measurements of the deposition coefficient for ice, and its application to cirrus seeding, Q. J. Roy. Meteor. Soc., 103, 307-318, doi:10.1002/qj.49710343608, 1977.

Connolly, P. J., Möhler, O., Field, P. R., Saathoff, H., Burgess, R., Choularton, T., and Gallagher, M.: Studies of heterogeneous freezing by three different desert dust samples, Atmos. Chem. Phys., 9, 2805-2824, doi:10.5194/acp-9-2805-2009, 2009.

Connolly, P. J., Emersic, C., and Field, P. R.: A laboratory investigation into the aggregation efficiency of small ice crystals, Atmos. Chem. Phys., 12, 2055-2076, doi:10.5194/acp-12-20552012, 2012.

Cotton, R. J., Benz, S., Field, P. R., Möhler, O., and Schnaiter, M.: Technical Note: A numerical test-bed for detailed ice nucleation studies in the AIDA cloud simulation chamber, Atmos. Chem. Phys., 7, 243-256, doi:10.5194/acp-7-243-2007, 2007.
Cullen, A. C. and Frey, H. C.: Probabilistic Techniques in Exposure Assessment: A Handbook for Dealing with Variability and Uncertainty in Models and Inputs, Plenum Press, New York, 335 pp., 1999.

Dahneke, B.: Simple Kinetic Theory of Brownian Diffusion in Vapors and Aerosols, in: Theory of Dispersed Multiphase Flow, edited by: Meyer, R. E., Academic Press, New York, 97-133, 1983.

Dearden, C., Connolly, P. J., Choularton, T. W., and Field, P. R.: Evaluating the effects of microphysical complexity in idealised simulations of trade wind cumulus using the Factorial Method, Atmos. Chem. Phys., 11, 2729-2746, doi:10.5194/acp-11-27292011, 2011.

Earle, M. E., Kuhn, T., Khalizov, A. F., and Sloan, J. J.: Volume nucleation rates for homogeneous freezing in supercooled water microdroplets: results from a combined experimental and modelling approach, Atmos. Chem. Phys., 10, 7945-7961, doi:10.5194/acp-10-7945-2010, 2010.

Ebert, V., Teichert, H., Giesemann, C., Saathoff, H., and Schurath, U.: Fibre-coupled in-situ laser absorption spectrometer for the selective detection of water vapour traces down to the ppb-level, Tech. Mess., 72, 23-30, doi:10.1524/teme.72.1.23.56689, 2005.

Fahey, D. W., Gao, R. S., and Möhler, O.: Summary of the AquaVIT Water Vapor Intercomparison: Static Experiments, available at: https://aquavit.icg.kfa-juelich.de/AquaVit/AquaVitWiki, 2009.

Feistel, R. and Wagner, W.: Sublimation pressure and sublimation enthalpy of $\mathrm{H}_{2} \mathrm{O}$ ice Ih between 0 and $273.16 \mathrm{~K}$, Geochim. Cosmochim. Ac., 71, 36-45, doi:10.1016/j.gca.2006.08.034, 2007.

Field, P. R., Cotton, R. J., Johnson, D., Noone, K., Glantz, P., Kaye, P. H., Hirst, E., Greenaway, R. S., Jost, C., Gabriel, R., Reiner, T., Andreae, M., Saunders, C. P. R., Archer, A., Choularton, T., Smith, M., Brooks, B., Hoell, C., Bandy, B., and Heymsfield, A.: Ice nucleation in orographic wave clouds: Measurements made during INTACC, Q. J. Roy. Meteor. Soc., 127, 1493-1512, doi:10.1002/qj.49712757502, 2001.

Field, P. R., Wood, R., Brown, P. R. A., Kaye, P. H., Hirst, E., Greenaway, R., and Smith, J. A.: Ice Particle Interarrival Times Measured with a Fast FSSP, J. Atmos. Ocean. Tech., 20, 249261, doi:10.1175/1520-0426(2003)020<0249:ipitmw >2.0.co;2, 2003.

Fukuta, N. and Walter, L. A.: Kinetics of Hydrometeor Growth from a Vapor-Spherical Model, J. Atmos. Sci., 27, 1160-1172, 
doi:10.1175/1520-0469(1970)027<1160:kohgfa >2.0.co;2, 1970.

Gallavardin, S. J., Froyd, K. D., Lohmann, U., Möhler, O., Murphy, D. M., and Cziczo, D. J.: Single Particle Laser Mass Spectrometry Applied to Differential Ice Nucleation Experiments at the AIDA Chamber, Aerosol Sci. Technol., 42, 773-791, doi:10.1080/02786820802339538, 2008.

Gao, R. S., Popp, P. J., Fahey, D. W., Marcy, T. P., Herman, R. L., Weinstock, E. M., Baumgardner, D. G., Garrett, T. J., Rosenlof, K. H., Thompson, T. L., Bui, P. T., Ridley, B. A., Wofsy, S. C., Toon, O. B., Tolbert, M. A., Kärcher, B., Peter, T., Hudson, P. K., Weinheimer, A. J., and Heymsfield, A. J.: Evidence that nitric acid increases relative humidity in low-temperature cirrus clouds, Science, 303, 516-520, doi:10.1126/science.1091255, 2004.

Gayet, J.-F., Shcherbakov, V., Mannstein, H., Minikin, A., Schumann, U., Ström, J., Petzold, A., Ovarlez, J., and Immler, F.: Microphysical and optical properties of midlatitude cirrus clouds observed in the southern hemisphere during INCA, Q. J. Roy. Meteor. Soc., 132, 2719-2748, doi:10.1256/qj.05.162, 2006.

Gierens, K. M., Monier, M., and Gayet, J. F.: The deposition coefficient and its role for cirrus clouds, J. Geophys. Res., 108, 4069, doi:10.1029/2001jd001558, 2003.

Ghosh, S., Dobbie, S., Marsham, J., and Jonas, P.: On the importance of the diffusional uptake of water vapour for the development and radiative properties of high altitude clouds: a large eddy model sensitivity study, Q. J. Roy. Meteor. Soc., 133, 1731-1741, 2007.

Haag, W., Kärcher, B., Schaefers, S., Stetzer, O., Möhler, O., Schurath, U., Krämer, M., and Schiller, C.: Numerical simulations of homogeneous freezing processes in the aerosol chamber AIDA, Atmos. Chem. Phys., 3, 195-210, doi:10.5194/acp-3-195-2003, 2003.

Hall, W. and Pruppacher, H.,: The survival of ice particles falling from cirrus clouds in subsaturated air, J. Atmos. Sci., 33, 19952006, 1976.

Haynes, D. R., Tro, N. J., and George, S. M.: Condensation and evaporation of $\mathrm{H}_{2} \mathrm{O}$ on ice surfaces, J. Phys. Chem., 96, 85028509, doi:10.1021/j100200a055, 1992.

Isono, K. and Iwai, K.: Growth Mode of Ice Crystals in Air at Low Pressure, Nature, 223, 1149-1150, 1969.

Kärcher, B. and Lohmann, U.: A Parameterization of cirrus cloud formation: Homogeneous freezing including effects of aerosol size, J. Geophys. Res., 107, 4698, doi:10.1029/2001jd001429, 2002a.

Kärcher, B. and Lohmann, U.: A parameterization of cirrus cloud formation: Homogeneous freezing of supercooled aerosols, J. Geophys. Res., 107, 4010, doi:10.1029/2001jd000470, 2002 b.

Kärcher, B. and Lohmann, U.: A parameterization of cirrus cloud formation: Heterogeneous freezing, J. Geophys. Res., 108, 4402, doi:10.1029/2002jd003220, 2003.

Kärcher, B. and Ström, J.: The roles of dynamical variability and aerosols in cirrus cloud formation, Atmos. Chem. Phys., 3, 823838, doi:10.5194/acp-3-823-2003, 2003.

Kärcher, B., Hendricks, J., and Lohmann, U.: Physically based parameterization of cirrus cloud formation for use in global atmospheric models, J. Geophys. Res., 111, D01205, doi:10.1029/2005jd006219, 2006.

Kay, J. E. and Wood, R.: Timescale analysis of aerosol sensitivity during homogeneous freezing and implications for upper tropo- spheric water vapor budgets, Geophys. Res. Lett., 35, L10809, doi:10.1029/2007g1032628, 2008.

Koop, T., Luo, B. P., Tsias, A., and Peter, T.: Water activity as the determinant for homogeneous ice nucleation in aqueous solutions, Nature, 406, 611-614, doi:10.1038/35020537, 2000.

Korolev, A. and Isaac, G.: Roundness and Aspect Ratio of Particles in Ice Clouds, J. Atmos. Sci., 60, 1795-1808, doi:10.1175/15200469(2003)060<1795:RAAROP> 2.0.CO;2, 2003.

Kramers, H. and Stemerding, S.: The sublimation of ice in vacuum, Appl. Sci. Res., A3, 73-82, doi:10.1007/BF03184673, 1951.

Leu, M.-T.: Laboratory studies of sticking coefficients and heterogeneous reactions important in the Antarctic stratosphere, Geophys. Res. Lett., 15, 17-20, doi:10.1029/GL015i001p00017, 1988.

Libbrecht, K. G.: The physics of snow crystals, Rep. Prog. Phys., 68, 855, doi:10.1088/0034-4885/68/4/R03, 2005.

Lin, R. F., Starr, D. O., DeMott, P. J., Cotton, R., Sassen, K., Jensen, E., Kärcher, B., and Liu, X. H.: Cirrus Parcel Model Comparison Project. Phase 1: The critical components to simulate cirrus initiation explicitly, J. Atmos. Sci., 59, 2305-2329, doi:10.1175/1520-0469(2002)059<2305:CPMCPP>2.0.CO;2, 2002.

Liou, K.-N.: Influence of Cirrus Clouds on Weather and Climate Processes: A Global Perspective, Mon. Weather Rev., 114, 1167-1199, doi:10.1175/15200493(1986)114<1167:ioccow > 2.0.co;2, 1986.

Lohmann, U. and Feichter, J.: Global indirect aerosol effects: a review, Atmos. Chem. Phys., 5, 715-737, doi:10.5194/acp-5-7152005, 2005.

Lohmann, U., Spichtinger, P., Jess, S., Peter, T., and Smit, H.: Cirrus cloud formation and ice supersaturated regions in a global climate model, Environ. Res. Lett., 3, 045022, doi:10.1088/17489326/3/4/045022, 2008.

Magee, N., Moyle, A. M., and Lamb, D.: Experimental determination of the deposition coefficient of small cirrus-like ice crystals near $-50^{\circ} \mathrm{C}$, Geophys. Res. Lett., 33, L17813, doi:10.1029/2006g1026665, 2006.

Marquardt, D. W.: An Algorithm for Least-Squares Estimation of Nonlinear Parameters, J. Soc. Indust. Appl. Math., 11, 431-441, doi:10.1137/0111030, 1963.

Massman, W. J.: A review of the molecular diffusivities of $\mathrm{H}_{2} \mathrm{O}$, $\mathrm{CO}_{2}, \mathrm{CH}_{4}, \mathrm{CO}, \mathrm{O}_{3}, \mathrm{SO}_{2}, \mathrm{NH}_{3}, \mathrm{~N}_{2} \mathrm{O}, \mathrm{NO}$, and $\mathrm{NO}_{2}$ in air, $\mathrm{O}_{2}$ and $\mathrm{N}_{2}$ near STP, Atmos. Environ., 32, 1111-1127, 1998.

McDonald, J. E.: Use of the electrostatic analogy in studies of ice crystal growth, Z. Angew. Math. Phys., 14, 610-620, doi:10.1007/bf01601268, 1963.

McFarquhar, G. M., Um, J., Freer, M., Baumgardner, D., Kok, G. L., and Mace, G.: Importance of small ice crystals to cirrus properties: Observations from the Tropical Warm Pool International Cloud Experiment (TWP-ICE), Geophys. Res. Lett., 34, L13803, doi:10.1029/2007g1029865, 2007.

Miles, R. E. H., Reid, J. P., and Riipinen, I.: Comparison of Approaches for Measuring the Mass Accommodation Coefficient for the Condensation of Water and Sensitivities to Uncertainties in Thermophysical Properties, J. Phys. Chem. A, 116, 1081010825, 2012.

Mitchell, D. L., Lawson, R. P., and Baker, B.: Understanding effective diameter and its application to terrestrial radiation in ice clouds, Atmos. Chem. Phys., 11, 3417-3429, doi:10.5194/acp- 
11-3417-2011, 2011.

Möhler, O., Stetzer, O., Schaefers, S., Linke, C., Schnaiter, M., Tiede, R., Saathoff, H., Krämer, M., Mangold, A., Budz, P., Zink, P., Schreiner, J., Mauersberger, K., Haag, W., Kärcher, B., and Schurath, U.: Experimental investigation of homogeneous freezing of sulphuric acid particles in the aerosol chamber AIDA, Atmos. Chem. Phys., 3, 211-223, doi:10.5194/acp-3-211-2003, 2003.

Möhler, O., Büttner, S., Linke, C., Schnaiter, M., Saathoff, H., Stetzer, O., Wagner, R., Krämer, M., Mangold, A., Ebert, V., and Schurath, U.: Effect of sulfuric acid coating on heterogeneous ice nucleation by soot aerosol particles, J. Geophys. Res., 110, D11210, doi:10.1029/2004jd005169, 2005.

Möhler, O., Field, P. R., Connolly, P., Benz, S., Saathoff, H., Schnaiter, M., Wagner, R., Cotton, R., Krämer, M., Mangold, A., and Heymsfield, A. J.: Efficiency of the deposition mode ice nucleation on mineral dust particles, Atmos. Chem. Phys., 6, 30073021, doi:10.5194/acp-6-3007-2006, 2006.

Morrison, H. and Gettelman, A.: A New Two-Moment Bulk Stratiform Cloud Microphysics Scheme in the Community Atmosphere Model, Version 3 (CAM3). Part I: Description and Numerical Tests, J. Climate, 21, 3642-3659, doi:10.1175/2008JCLI2105.1, 2008.

Mozurkewich, M.: Aerosol Growth and the Condensation Coefficient for Water: A Review, Aerosol Sci. Technol., 5, 223-236, doi:10.1080/02786828608959089, 1986.

Murphy, D. M. and Koop, T.: Review of the vapour pressures of ice and supercooled water for atmospheric applications, Q. J. Roy. Meteor. Soc., 131, 1539-1565, doi:10.1256/qj.04.94, 2005.

Nelson, J. T. and Baker, M. B.: New theoretical framework for studies of vapor growth and sublimation of small ice crystals in the atmosphere, J. Geophys. Res., 101, 7033-7047, doi:10.1029/95jd03162, 1996.

Peter, T., Marcolli, C., Spichtinger, P., Corti, T., Baker, M. B., and Koop, T.: When dry air is too humid, Science, 314, 1399-1402, doi:10.1126/science.1135199, 2006.

Pratte, P., van den Bergh, H., and Rossi, M. J.: The kinetics of $\mathrm{H}_{2} \mathrm{O}$ vapor condensation and evaporation on different types of ice in the range 130-210 K, J. Phys. Chem. A, 110, 3042-3058, doi:10.1021/jp053974s, 2006.

Press, W. H., Teukolsky, S. A., Vetterling, W. T., and Flannery, B. P.: Numerical Recipes: The Art of Scientific Computing, 3rd Edn., Cambridge Univ. Press, Cambridge, 1235 pp., 2007.

Pruppacher, H. R. and Klett, J. D.: Microphysics of Clouds and Precipitation, 2nd Edn., Kluwer Academic Publishers, Dordrecht, 954 pp., 1997.

Rubinstein, R. Y. and Kroese, D. P.: Simulation and the Monte Carlo Method, 2nd Edn., John Wiley \& Sons, Hoboken, New Jersey, 345 pp., 2008.
Saunders, R. W., Möhler, O., Schnaiter, M., Benz, S., Wagner, R., Saathoff, H., Connolly, P. J., Burgess, R., Murray, B. J., Gallagher, M., Wills, R., and Plane, J. M. C.: An aerosol chamber investigation of the heterogeneous ice nucleating potential of refractory nanoparticles, Atmos. Chem. Phys., 10, 1227-1247, doi:10.5194/acp-10-1227-2010, 2010.

Schnaiter, M., Büttner, S., Möhler, O., Skrotzki, J., Vragel, M., and Wagner, R.: Influence of particle size and shape on the backscattering linear depolarisation ratio of small ice crystals - cloud chamber measurements in the context of contrail and cirrus microphysics, Atmos. Chem. Phys., 12, 10465-10484, doi:10.5194/acp-12-10465-2012, 2012.

Skrotzki, J.: High-accuracy multiphase humidity measurements using TDLAS: application to the investigation of ice growth in simulated cirrus clouds, Combined Faculties for the Natural Sciences and for Mathematics, Ruperto-Carola University, Heidelberg, 140 pp., 2012.

Skrotzki, J., Habig, J. C., and Ebert, V.: Integrative fitting of absorption line profiles with high accuracy, robustness, and speed, Appl. Phys. B, in review, 2013.

Spichtinger, P. and Gierens, K. M.: Modelling of cirrus clouds Part 1a: Model description and validation, Atmos. Chem. Phys., 9, 685-706, doi:10.5194/acp-9-685-2009, 2009.

Twomey, S.: Pollution and the planetary albedo, Atmos. Environ., 8, 1251-1256, doi:10.1016/0004-6981(74)90004-3, 1974.

Vragel, M.: Messung klimarelevanter optischer Eigenschaften von Mineralstaub im Labor, Faculty of Physics, Karlsruhe Institute of Technology, Karlsruhe, 162 pp., 2009.

Wagner, R., Linke, C., Naumann, K.-H., Schnaiter, M., Vragel, M., Gangl, M., and Horvath, H.: A review of optical measurements at the aerosol and cloud chamber AIDA, J. Quant. Spectrosc. Ra., 110, 930-949, doi:10.1016/j.jqsrt.2009.01.026, 2009.

Weast, R. C., Astle, M. J., and Beyer, W. H.: CRC Handbook of Chemistry and Physics, 68th Edn., CRC Press, Boca Raton, Florida, 1987.

Westbrook, C. D. and Heymsfield, A. J.: Ice Crystals Growing from Vapor in Supercooled Clouds between $-2.5^{\circ}$ and $-22^{\circ} \mathrm{C}$ : Testing Current Parameterization Methods Using Laboratory Data, J. Atmos. Sci., 68, 2416-2429, 2011.

Westbrook, C. D., Hogan, R. J., and Illingworth, A. J.: The Capacitance of Pristine Ice Crystals and Aggregate Snowflakes, J. Atmos. Sci., 65, 206-219, doi:10.1175/2007jas2315.1, 2008.

Zhang, Y., Macke, A., and Albers, F.: Effect of crystal size spectrum and crystal shape on stratiform cirrus radiative forcing, Atmos. Res., 52, 59-75, doi:10.1016/s0169-8095(99)00026-5, 1999. 